Florida International University

FIU Digital Commons

$6-25-2020$

\title{
Use of Laser Induced Breakdown Spectroscopy For the Detection and Analysis of Chemical Taggants
}

Cole Andrew Pajunen

Florida International University, cpaju002@fiu.edu

Follow this and additional works at: https://digitalcommons.fiu.edu/etd

Part of the Analytical Chemistry Commons

\section{Recommended Citation}

Pajunen, Cole Andrew, "Use of Laser Induced Breakdown Spectroscopy For the Detection and Analysis of Chemical Taggants" (2020). FIU Electronic Theses and Dissertations. 4508.

https://digitalcommons.fiu.edu/etd/4508

This work is brought to you for free and open access by the University Graduate School at FIU Digital Commons. It has been accepted for inclusion in FIU Electronic Theses and Dissertations by an authorized administrator of FIU Digital Commons. For more information, please contact dcc@fiu.edu. 


\title{
FLORIDA INTERNATIONAL UNIVERSITY
}

Miami, Florida

\section{USE OF LASER INDUCED BREAKDOWN SPECTROSCOPY FOR THE DETECTION AND ANALYSIS OF CHEMICAL TAGGANTS}

\author{
A thesis submitted in partial fulfillment of \\ the requirements for the degree of \\ MASTER OF SCIENCE \\ in \\ FORENSIC SCIENCE \\ by
}

Cole Andrew Pajunen 
To: Dean Michael R. Heithaus

College of Arts, Sciences and Education

This thesis, written by Cole Andrew Pajunen, and entitled Use of Laser Induced Breakdown Spectroscopy for the Detection and Analysis of Chemical Taggants, having been approved in respect to style and intellectual content, is referred to you for judgment.

We have read this thesis and recommend that it be approved.

Anthony De Caprio

Piero Gardinali

Jose Almirall, Major Professor

Date of Defense: June 25, 2020

The thesis of Cole Andrew Pajunen is approved.

Dean Michael R. Heithaus

College of Arts, Sciences and Education

Andrés G. Gil

Vice President for Research and Economic Development and Dean of the University Graduate School

Florida International University, 2020 


\title{
ABSTRACT OF THE THESIS \\ USE OF LASER INDUCED BREAKDOWN SPECTROSCOPY FOR THE DETECTION AND ANALYSIS OF CHEMICAL TAGGANTS
}

\author{
by \\ Cole Andrew Pajunen \\ Florida International University, 2020 \\ Miami, Florida \\ Professor Jose Almirall, Major Professor
}

Chemical taggants impart a unique imprint on an object so that the ownership or original source can be unambiguously identified. A commercially available tagging system from SmartWater ${ }^{\circledR}$ Technology Ltd. utilizes a polymer-based solution that solidifies upon application and contains a unique combination of up to 27 metals as the chemical identification system. Currently, Laser ablation inductively coupled mass spectrometry (LA-ICP-MS) is used as the primary means to determine the presence/absence of these elements. The current study investigates the use of a commercial laser induced breakdown spectroscopy (LIBS) system as an alternative detection method because of its ease of use and cost effectiveness. The LIBS system was able to discriminate between 18 and 19 elements using nanosecond-Nd:YAG $266 \mathrm{~nm}$ and $1064 \mathrm{~nm}$ lasers, respectively, at the concentrations present in the quality control (QC) solution. No elements could be identified once the QC solution was diluted by a factor of 10 . 
TABLE OF CONTENTS

CHAPTER

PAGE

CHAPTER 1: MOTIVATION FOR RESEARCH AND RESEARCH HYPOTHESIS ....1

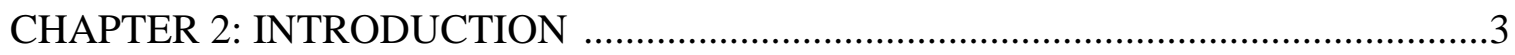

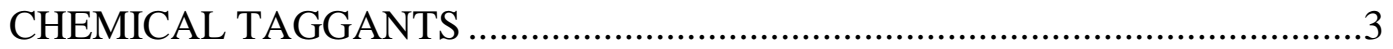

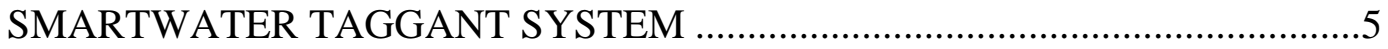

ELEMENTAL ANALYSIS TECHNIQUES..................................................

APPLICATIONS AND POTENTIAL OF LASER INDUCED BREAKDOWN

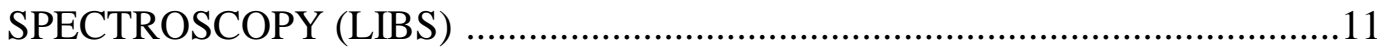

CHAPTER 3: LIBS INSTRUMENTATION AND OPTIMIZATION …………............15

LIBS MACHINES AND SAMPLES UTILIZED FOR EXPERIMENTS ...........15

POWER OUTPUT OPTIMIZATION …………….....................................17

GATE DELAY AND GATE WIDTH ………….....................................18

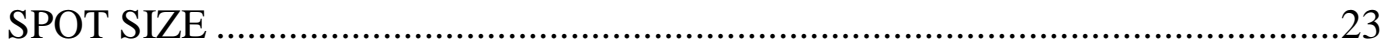

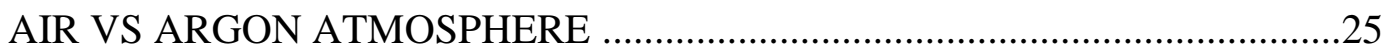

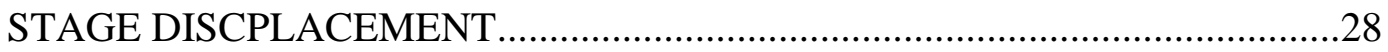

OPTIMIZED RESULTS OF THE 266 NM AND 1064 NM LASER...................30

CHAPTER 4: DILUTIONS AND ANALYSIS OF DIFFERENT SOLUTIONS .............34

EFFECT OF DILUTIONS ON 266 NM LASER RESULTS ................................34

EFFECT OF DILUTIONS ON 1064 NM LASER RESULTS .............................37

DIFFERENT QUALITY CONTROL SOLUTIONS ........................................42

CHAPTER 5: INTERPRETATION AND DISCUSSION ........................................48

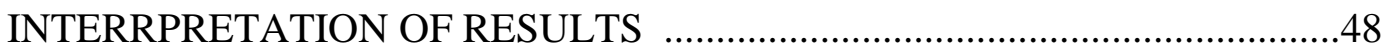

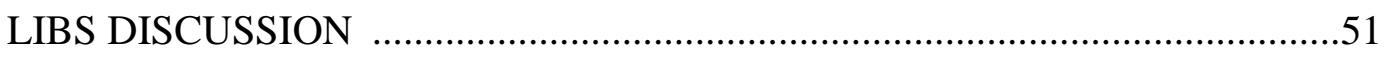

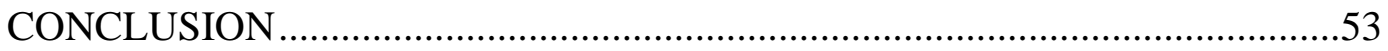

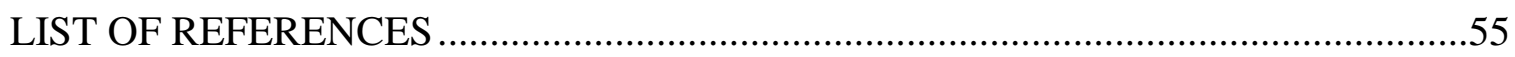




\section{LIST OF TABLES}

TABLE

PAGE

Table 1: Elements detected using $266 \mathrm{~nm}$ laser along with their respective wavelengths used for identification and their concentration in the Tracer QC solution. .31

Table 2: Elements detected using $1064 \mathrm{~nm}$ laser along with their respective wavelengths used for identification and their concentration in the Tracer QC solution. .32

Table 3: Elements detected using $266 \mathrm{~nm}$ laser along with their respective wavelengths used for identification and their concentration when elements in the tracer QC solution were at $\frac{3}{4}$ of their original concentration

Table 4: Elements detected using $266 \mathrm{~nm}$ laser along with their respective wavelengths used for identification and their concentration when elements in the tracer QC solution were at $\frac{2}{3}$ of their original concentration

Table 5: Elements detected using $266 \mathrm{~nm}$ laser along with their respective wavelengths used for identification and their concentration when the tracer QC solution was diluted by a factor of 2

Table 6: Elements detected using $266 \mathrm{~nm}$ laser along with their respective wavelengths used for identification and their concentration when the QC solution was diluted by a factor of 3

Table 7: Elements detected using $266 \mathrm{~nm}$ laser along with their respective wavelengths used for identification and their concentration when the QC solution was diluted by a factor of 4

Table 8: Elements detected using $266 \mathrm{~nm}$ laser along with their respective wavelengths used for identification and their concentration when the QC solution was diluted by a factor of 5

Table 9: Elements detected using $1064 \mathrm{~nm}$ laser along with their respective wavelengths used for identification and their concentration when elements in the tracer QC solution were at $\frac{3}{4}$ of their original concentration 
Table 10: Elements detected using $1064 \mathrm{~nm}$ laser along with their respective wavelengths used for identification and their concentration when elements in the tracer QC solution were at $\frac{2}{3}$ of their original concentration

Table 11: Elements detected using $1064 \mathrm{~nm}$ laser along with their respective wavelengths used for identification and their concentration when the tracer QC solution was diluted by a factor of 2

Table 12: Elements detected using 1064 nm laser along with their respective wavelengths used for identification and their concentration when the tracer QC solution was diluted by a factor of 3

Table 13: Elements detected using $1064 \mathrm{~nm}$ laser along with their respective wavelengths used for identification and their concentration when the tracer QC solution was diluted by a factor of 4

Table 14: Elements detected using $1064 \mathrm{~nm}$ laser along with their respective wavelengths used for identification and their concentration when the QC solution was diluted by a factor of 5

Table 15: Elements detected using $266 \mathrm{~nm}$ laser along with their respective wavelengths used for identification and their concentration in the Index QC solution ....44

Table 16: Elements detected using the $266 \mathrm{~nm}$ laser along with their respective wavelengths used for identification in the high temperature QC solution

Table 17: Elements detected using J200 laser along with their respective wavelengths used for identification in the heavy duty Marker QC solution 


\section{LIST OF FIGURES}

FIGURE

PAGE

Figure 1: Schematic diagram of a simple LIBS system. .11

Figure 2: Power output effect on $\mathrm{S} / \mathrm{N}$ for $266 \mathrm{~nm}$ laser

Figure 3: Power output effect on $\mathrm{S} / \mathrm{N}$ for $1064 \mathrm{~nm}$ laser. .18

Figure 4: Gate Delay effect on $\mathrm{S} / \mathrm{N}$ for the $266 \mathrm{~nm}$ laser .20

Figure 5: Gate Delay effect on $\mathrm{S} / \mathrm{N}$ for the $1064 \mathrm{~nm}$ laser for both ionic (right) and neutral (left) elements

Figure 6: Gate width effect on $\mathrm{S} / \mathrm{N}$ on $266 \mathrm{~nm}$ laser

Figure 7: Gate width effect on S/N on $1064 \mathrm{~nm}$ laser for ionic (bottom) and neutral (top) elements

Figure 8: Spot size effect on $\mathrm{S} / \mathrm{N}$ ratios for $266 \mathrm{~nm}$ laser.

Figure 9: Spot size effect on $\mathrm{S} / \mathrm{N}$ ratios for the $1064 \mathrm{~nm}$ laser .25

Figure 10: S/N ratios for europium, ytterbium, and molybdenum in air and in an argon environment .26

Figure 11: Argon vs Air environment effect on results from $1064 \mathrm{~nm}$ laser.....

Figure 12: Surface defocusing effect on $\mathrm{S} / \mathrm{N}$ for $\mathrm{Ba}$ at $455.403 \mathrm{~nm}$ using $266 \mathrm{~nm}$ laser ..28

Figure 13: Surface defocusing effect on $\mathrm{S} / \mathrm{N}$ ratios using $1064 \mathrm{~nm}$ laser for ionic (bottom) and neutral (top) elements. 


\section{CHAPTER 1: MOTIVATION FOR RESEARCH AND RESEARCH HYPOTHESIS}

When it comes to elemental analysis, techniques such as ICP-MS and LA-ICP-MS are the current gold standard because of the high sensitivity of these techniques. However, while these methods have been shown to be accurate even at concentrations in the parts per billion ( $\mathrm{ppb}$ ) range, there are drawbacks that make alternative approaches seem appealing [1]. One of these methods is known as laser induced breakdown spectroscopy (LIBS). Compared to ICP-MS and LA-ICP-MS, LIBS is a simpler and quicker method for obtaining results when performing elemental analysis. It does not require complex sample preparation for it to function nor does it require a separate mass spectrometry machine that needs to be maintained and kept under vacuum [2]. In addition, while a new ICP-MS system can cost as much $\$ 250,000$, a new LIBS machine will generally be much cheaper and go for only around $\$ 50,000$ [3]. These costs do not reflect the price to run a sample, which for LA-ICP-MS requires both a constant stream of argon and helium gas whereas LIBS can be run in air under atmospheric conditions (although having an argon atmosphere may improve results) [3][4]. Lastly, LIBS has the potential of becoming a portable system [5]. Not only would this give quick results, it would also eliminate the need to collect and preserve samples for analysis, meaning that a sample can be analyzed at a point of interest without needing to worry about degradation and introducing contaminants during sampling.

The present research is concerned with how viable LIBS is compared to ICP-MS and LA-ICP-MS when it comes to elemental analysis. Specifically, how well LIBS works with identifying the elements that are utilized in chemical tagging systems such as the 
formula utilized by SmartWater ${ }^{\circledR}$ Technology. While LA-ICP-MS is capable of detecting every element used in SmartWater ${ }^{\circledR}$ solutions, LIBS was studied as an alternative method [6]. Two LIBS machines were purchased and used for the study, one with a $27 \mathrm{~mJ}, 266 \mathrm{~nm}$ laser and one with a $50 \mathrm{~mJ}, 1064 \mathrm{~nm}$ laser. It was expected that LIBS would have the same or a similar level of discrimination as LA-ICP-MS for detecting the elements used in SmartWater ${ }^{\circledR}$ solutions. In addition, since the $1064 \mathrm{~nm}$ laser had more energy per laser shot than its $266 \mathrm{~nm}$ counterpart, it was expected that it would be able to detect more elements while also improving on the results from the $266 \mathrm{~nm}$ laser. 


\section{CHAPTER 2: INTRODUCTION}

\section{CHEMICAL TAGGANTS}

As the complexities of crime and counterfeiting increase, so too must the methods be to identify and prevent them. One of the more common methods employed to combat these issues are chemical taggants. These are any sort of detectable or individualized marking placed on an item of interest that allows it to become uniquely identifiable [9]. While many applications exist for such a product, they are generally utilized by law enforcement for four specific purposes. The first is to help certify that a marketed product comes from a legitimate origin in order to combat the growing problem of counterfeit activities [9]. The second purpose is to aide in the problem of theft by uniquely marking an item so that it is associated with an owner [9]. If a stolen item is recovered by police, it can be traced back, without doubt, to the individual it belongs to. The third goal is to monitor and track the use and sale of illicit substances which is done by adding a taggant to an object and making note of where the tagged item is seen as it is distributed [9]. Finally, a taggant can be utilized to track a criminal that has left the scene of a crime [9]. Marking a criminal in this manner is achieved using a transferrable material that can be passed on to a person while a crime is taking place [9].

Currently, taggants are most often used in distinguishing counterfeit goods from their legitimate counterparts. As of 2017, counterfeit consumer goods, ranging from handbags to medicines, have introduced over a trillion-dollar loss across various industries worldwide, leading to thousands of lost jobs [7]. In fact, over $10 \%$ of all medicines and 
electronic components sold are not of genuine origin [12]. While physical tags, such as a hologram, watermark, or microdot have been popular in the past, counterfeiters have been quick to mimic these to make their goods look indistinguishable from the legitimate product [10]. As such, more complex forms of identification have come in the form of chemical taggants. These utilize small amounts of a small chemical compound that cannot be detected using the naked eye. Peptide sequences, nanoparticles, liquid crystals, etc. can be easily be spiked onto an item and tested at a subsequent date to confirm authenticity [9] [13]. Unlike many physical taggants, these cannot be as easily replicated since their exact conformation or sequence cannot be determined without advanced instrumentation.

Taggants are also used for counterterrorism and homeland security applications, particularly in the detection of various explosives. Most countries around the world are mandated to include certain taggants in the explosives they make, as is detailed in the 1998 International Civil Aviation Organization's Convention on the Marking of Explosives for the Purpose of Identification [8]. In general, the taggants used in explosives are of high vapor pressure and must be easily detected in the air surrounding the explosive compounds [14]. They are also unreactive with the explosives and have a high stability over a long period of time [8]. The molecules that meet these requirements are often volatile organic nitrates and include compounds such as 2-nitrotoluene (2-NT), 4-nitrotoluene (4-NT) and 2,3-dimethyl-2,3-dinitrobutane (DMDNB) [14]. The compounds used can then be easily identified using an ion mobility spectrometer or, if one needs to perform a quick presumptive test, a trained dog. If an even more specific taggant (such as a nanoparticle) is utilized, the explosive can then be traced to a specific point of origin, saving law enforcement valuable time in the process [15][8]. 
While anti-theft and suspect tracking taggants are a relatively newer phenomena, it has attracted the attention of businesses looking to protect intellectual property. They work by using stable and easily transferrable compounds that can be applied to goods which can then be traced back to the original owner if stolen. These compounds can also be utilized by being transferred to people involved in an active crime scene. The taggants used are generally composed of a medium that, while invisible to the naked eye to avoid unwanted detection, can easily be identified using different light sources [9]. The actual coding element(s) inside the medium can then be identified after collection [9]. The coding compounds are what make the tags unique. For example, researchers were able to make a transferrable solution consisting of Rhodamine-110 fluorophores and unique peptide sequences [9]. The fluorophores allowed the solution to be detected only when a specific light source was applied and the specific peptides were what made each sample unique [9]. If the solution was applied to either a criminal or high valued object, law enforcement can easily identify the taggant and the "code" can be analyzed and confirmed in a laboratory. The research in my thesis addresses the analysis of another commercially available tagging system. Instead of using peptide sequences, though, the taggant instead employs a combination of metals to make a unique formulation.

\section{SMARTWATER TAGGANT SYSTEM}

Founded in 1993, SmartWater ${ }^{\circledR}$ Technology Ltd., a company founded in the United Kingdom, created its own way to not only link objects with an owner but to also link individuals to crime scenes. They created a solution that, under normal circumstances, cannot be detected while also allowing for unambiguous identification after recovery [16]. 
The bulk of any SmartWater ${ }^{\circledR}$ product is made up of a water-based polymer. When the solution is shipped out to a customer, it comes as a liquid. However, after application to an object or person, the polymer solidifies where it creates a thin layer that is invisible to the naked eye [16]. When a sample of the tagged object or person is recovered, it is then screened to see if the SmartWater ${ }^{\circledR}$ solution might be present. Screening is done by shining a UV light on the area suspected to contain the solution. The polymer utilized by SmartWater® fluoresces as a bright yellow or green color when exposed to ultraviolet light. If an item is thought to contain SmartWater ${ }^{\circledR}$, it is then brought to a lab to confirm if the taggant present matches the formulation sent to the person who originally bought the solution. The taggant used in SmartWater ${ }^{\circledR}$ is made up of a combination of up to 16 rare earth elements as well as 11 other metals. The elements used do not occur very often in nature, meaning that if an element is found, it can be said to have originated from the solution as opposed to the object(s) it is attached to. Each solution is unique since it could contain any number of the elements used in SmartWater ${ }^{\circledR}$ formulations. Therefore, linking a solution back to an owner will be based on the elemental composition of the recovered sample. The present study evaluated the Tracer, Index, High Temperature, and Heavy-Duty

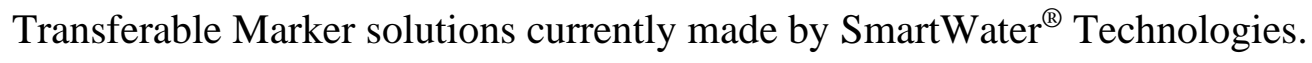

Analysis of the elemental composition of each of these solutions is key for detecting the unique taggant. SmartWater® Technology Ltd. maintains a database of each solution, which contains a unique elemental formulation, that can be cross-referenced to a specific customer [16]. Therefore, it is essential for the elemental analysis to be correct. The research in this thesis investigates the reliability of a newer technique used for elemental 
analysis to determine how well it can detect the elements in each of the four solutions and how it compares to the method that is traditionally used for analysis.

\section{ELEMENTAL ANALYSIS TECHNIQUES}

To detect the specific taggants used in SmartWater ${ }^{\circledR}$ samples, elemental analysis needs to be utilized. While a variety of techniques can perform elemental analysis, the most common instruments used include atomic absorption spectroscopy (AAS), x-ray fluorescence (XRF), inductively coupled plasma - optical emission spectroscopy (ICPOES), inductively coupled plasma - mass spectrometry (ICP-MS), laser ablation inductively coupled plasma - mass spectrometry (LA-ICP-MS), and laser induced breakdown spectroscopy (LIBS). These techniques have consistently demonstrated their ability to perform efficient elemental analysis. However, based on analytical capabilities and ease of use, their utility may differ when it comes to identifying the taggants used in SmartWater ${ }^{\circledR}$ samples.

Atomic absorption spectroscopy can detect elements in a sample using the wavelengths of light that are absorbed. A general AAS device will consist of a light source, a sample cell that will atomize a given sample, and a detector [17]. Once a sample is completely atomized, the light source will provide photons at a specific wavelength [18]. The atoms in the sample will absorb the light which excites their electrons. Then, the electrons will relax and transmit light at a specific wavelength, depending on the element [18]. The detector will then measure the wavelengths transmitted by the atoms and compare them to the wavelengths that were originally transmitted. The resulting spectrum (which generally ranges from 190-900 nm) will show how much absorption occurs at a given 
wavelength of light with each element absorbing at different wavelengths [18]. The signal measures the amount of energy that was absorbed, which is used to calculate the amount of a specific element in the sample. While sensitivity often depends on the element being analyzed, AAS can generally detect elements that have a concentration in the parts per million (ppm) range [18].

$\mathrm{X}$-ray fluorescence, unlike AAS, is a non-destructive technique for determining the elemental composition of a sample [19]. It works by using a primary x-ray source that radiates the atoms in a sample. The primary $\mathrm{x}$-ray source uses high energy $\mathrm{x}$-rays that, when applied to a sample, leads to the ejection of inner shell electrons which is followed by emission, as the electrons move back to their ground state [19]. The emitted (or fluorescent) x-ray wavelengths are then measured with a detector and a spectrum is produced [19]. Each element produces a specific set of fluorescent x-rays, meaning that interpretation is made using the emitted wavelengths that are present in the resulting spectrum [19]. The intensity of each signal is proportional to the concentration of the element making XRF useful not only for qualitative analysis, but also for quantitative analysis [20]. While XRF is suitable for a wide range of matrices and can perform rapid multi-element screening, its main drawback is a sample must be at least 100 microns thick for this technique to be effective [21].

Inductively coupled plasma - optical emission spectroscopy is one of the most common techniques used for both elemental and trace analysis. It works by injecting a liquid into an argon gas plasma [22]. The solution is converted to an aerosol prior to being introduced to the plasma where the extreme heat (around 10,000K) causes atomization and 
ionization of the sample [22]. Both the atoms and ions are brought to their excited states as a result of the high energy produced by the plasma. The electrons then quickly drop back down to their ground states which produces photons [23]. These emitted photons are then picked up by a spectrometer and a spectrum is made showing the intensity of each wavelength produced [23]. The resulting spectrum allows one to know what elements are present in the solution since each element will emit at very specific wavelengths [23]. In addition, the intensity of a wavelength can be measured and quantified into a concentration. Not only can ICP-OES allow for simultaneous analysis of more than 60 elements at a time, it can do so at very low concentrations [23]. The ICP-OES method is so sensitive that it can detect some elements in the parts per billion range in a given sample [23]. However, unlike XRF, ICP-OES is destructive and sample preparation can become an issue. While liquid and gas samples can be sent straight to the instrument, solid samples must first be prepared, either through extraction or acid digestion, prior to injection [23].

Inductively coupled plasma - mass spectrometry works similarly to ICP-OES, except that instead of detecting the emission wavelengths produced by the plasma, elements are instead detected using mass spectrometry. As with ICP-OES, samples must first be liquefied before being introduced to the plasma. It is most common for the liquid to be brought to the plasma through a nebulizer and spray chamber [23]. The nebulizer is what turns the liquid into an aerosol and the spray chamber is what ensures that only the smallest diameter particles are brought to the plasma [24]. The high energy plasma is what causes the atoms to become ionized. The charged atoms are then focused and brought to the mass spectrometer for analysis with a focusing lens [23]. The mass spectrometer then sorts the atoms on the basis of their mass to charge $(\mathrm{m} / \mathrm{z})$ ratio. The resulting graph shows 
all the $\mathrm{m} / \mathrm{z}$ ratios along with their intensities which lets an analyst know not only what elements are present but what their concentrations are in a sample [24]. Similar to ICPOES, ICP-MS has a very low detection limit for most elements (usually in the parts per billion range) [23]. However, instead of relying on excitation and emission of atoms, it instead uses a mass spectrometer to count the ionized species for its analysis.

Laser ablation - inductively coupled plasma - mass spectrometry is functionally similar to ICP-MS except that it introduces a sample to the ICP-MS system by using a high energy laser to ablate, or remove, a small amount of a sample which is then brought to the mass spectrometer. The main difference between the two techniques is that LA-ICP-MS requires only minimum sample preparation and is far less destructive compared to ICP-MS since it only removes nanogram quantities of a sample [25]. It works by focusing a high energy laser beam onto the surface of a solid [26]. The laser is fired and fine particles are ablated from the sample. The particles are then removed through the use of a carrier gas consisting of either argon or helium and brought to the ICP-MS system [25]. The atoms from the ablated particles are then ionized from the plasma and analyzed using mass spectrometry. Laser ablation - inductively coupled plasma - mass spectrometry has a sensitivity similar to that of ICP-MS all while needing very little sample preparation and being far less destructive. These qualities are what make it the current gold standard for conducting elemental analysis on SmartWater ${ }^{\circledR}$ samples. 


\section{APPLICATIONS AND POTENTIAL OF LASER INDUCED BREAKDOWN SPECTROSCOPY (LIBS)}

Laser induced breakdown spectroscopy (LIBS) is a tool used in analytical chemistry that, like LA-ICP-MS, utilizes a high energy laser that is focused on the surface of a sample in order to induce the formation of a plasma [5]. However, unlike LA-ICP-MS, LIBS does not need a gas to bring the ablated particles into a separate machine for separation and analysis. Instead, the energy from the laser will sustain a high temperature plasma $(>10,000 \mathrm{~K})$ where atoms, ions, and molecular fragments are excited and quickly return to their less energetic levels which will cause light to be emitted and subsequently observed using a spectrophotometer [5] [2]. Figure 1 shows the general set-up for a LIBS instrument. The wavelengths seen in the resulting spectrum can then be selectively traced to specific elements with the intensity of the peak(s) being roughly proportional to the amount of an element present in a sample. However, since the light from the plasma is short lived (usually lasting only around $20 \mu$ s), the results can lack precision, making LIBS a mostly semi-quantitative technique [2].

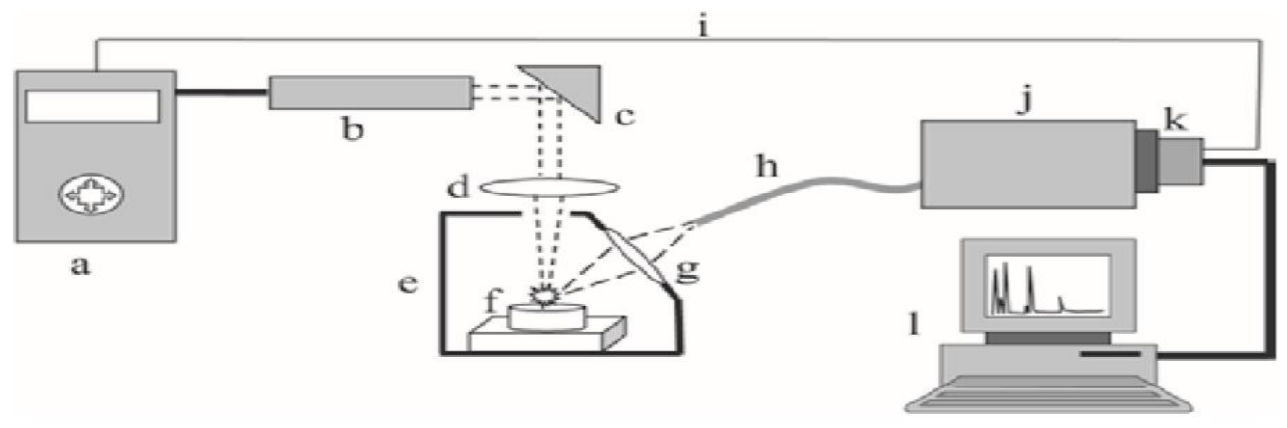

Figure 1: Schematic diagram of a simple LIBS system.(a) laser source and cooler; (b) pulsed laser head; (c) mirror; (d) focusing lens; (e) excitation chamber; (f) sample; (g) collecting optics; (h) optical fiber; (i) detector trigger signal; (j) wavelength selector; (k) detector array and (l) microcomputer. Adapted from "Laser Induced Breakdown Spectroscopy" by C. Pasquini, J. Cortez, L. Silva, and F.B. 
While LIBS is a much newer technique compared to some of the other methods described thus far, it has emerged as a beneficial tool for elemental analysis as a result of its simplicity and ease of use to obtain results. For example, LIBS has been used for analyzing alloys and other metallurgic samples since it can be employed directly on a solid sample without needing rigorous sample pre-treatment [2]. Lopez-Moreno et al. utilized a portable LIBS system when analyzing steel production processes. In particular, the researchers were able to analyze $\mathrm{Cr}, \mathrm{Mo}, \mathrm{Ni}, \mathrm{Mn}$, and $\mathrm{Si}$ in low alloy steel [27]. Loebe et al. observed glass and tool steel defects using LIBS. The researchers were able to identify any defects and contamination in steel and glass matrices thus showing the potential for LIBS to be used as a quality control tool for various industrial processes [28]. Corsi et al. used LIBS to analyze gold jewelry. In particular, it was shown that LIBS could be useful for quantifying concentrations of the elements $\mathrm{Au}, \mathrm{Ag}, \mathrm{Cu}$, and $\mathrm{Pd}$ in the precious alloys commonly used in jewelry [29].

In addition to analyzing metals and alloys, LIBS has also been an effective tool for a variety of environmental applications. As with metal and alloy samples, the simplicity and ease of use of LIBS has made it popular with those who want to perform elemental analysis on a variety of samples found in nature. For example, Niu et al. was able to determine the presence of strontium in marine algae [30]. Usually, collected samples would require digestion prior to analysis and the results would often have a strong interference of calcium. However, LIBS was able to analyze the algae without any digestion and the resulting spectra would not have any calcium interference [30]. Gondal and Hussain were able to quantify a variety of toxic metals in wastewater that was collected from a local paint manufacturing plant such as $\mathrm{Pb}, \mathrm{Cu}, \mathrm{Cr}, \mathrm{Ca}, \mathrm{S}, \mathrm{Mg}, \mathrm{An}, \mathrm{Ti}, \mathrm{Sr}, \mathrm{Ni}, \mathrm{Si}, \mathrm{Fe}, \mathrm{Al}, \mathrm{Ba}, \mathrm{Na}, \mathrm{K}$, 
and $\mathrm{Zr}$ [31]. All the elements were able to be seen with concentrations ranging from 1 to $301 \mu \mathrm{g} \mathrm{g}^{-1}$. These papers show that LIBS is able to detect elements that have concentrations in the ppm range which is particularly important as all of the elements used in SmartWater ${ }^{\circledR}$ samples range in concentration anywhere from 27-126 ppm [31].

When it comes to using LIBS as a tool for the detection of chemical taggants, a paper published by Steven Wise showed the potential for LIBS to be used to analyze SmartWater ${ }^{\circledR}$ samples. Wise successfully used LIBS to identify 17 of the 22 elements used in SmartWater ${ }^{\circledR}$ at the time [6]. He also made a list of what elements he could see, what concentrations were used for detection, and what the corresponding signal-to-noise ratios were (which gives an idea of the relative strength of the signals). For four elements, the LIBS machines were able to detect them but only at a much higher concentration (around 16x) than what was typically present in SmartWater ${ }^{\circledR}$ samples [6]. In addition, tellurium was not able to be observed using LIBS at any concentration [6]. Despite the limitations of his study, Wise was able to demonstrate how effective LIBS could be for identifying the various elements in SmartWater ${ }^{\circledR}$ samples [6].

The aim of this research focuses on expanding the work done by Steven Wise. While there were only 22 elements used in SmartWater ${ }^{\circledR}$ solutions when Wise did his experiments, there are now up 27 elements meaning that an updated menu must be created that will tell what elements can be discerned as well as how well they can be detected. In addition, his SmartWater ${ }^{\circledR}$ solutions did not account for the variations between different types of samples. The Tracer, Index, Heavy-Duty marker, and High Temperature solutions not only have different elemental concentrations and configurations but also possess 
different amounts of the polymer that causes them to solidify. Knowing how these differences affect the results is essential to knowing the true potential of LIBS. Also, this research focuses on how diluting SmartWater ${ }^{\circledR}$ solutions affects the ability of LIBS to identify the elements of interest. Lastly, Wise did not use commercially available LIBS machines. The research in this paper primarily uses two LIBS instruments that were bought and are commercially available from Applied Spectra. Optimizing these machines are important since the parameters and results can be easily replicated if anyone else wishes to analyze SmartWater ${ }^{\circledR}$ samples. 


\section{CHAPTER 3: LIBS INSTRUMENTATION AND OPTIMIZATION}

\section{LIBS MACHINES AND SAMPLES UTILIZED FOR EXPERIMENTS}

Two different LIBS machines were obtained for the research. Both were J200 lasers with a Q-switched ND:YAG pulsed nanosecond laser bought by Applied Spectra. A separate spectrometer system consisting of a broadband high resolution Andor Mechelle 5000 spectrometer with and Andor iStar ICCD camera acting as a detector was used instead of the usual Aurora spectrometer that usually comes with the machine. The separate spectrometer was employed since the Andor spectrometers are thought to be more sensitive than the Aurora spectrometers. The primary difference between the two machines has to do with the wavelength of the lasers and their subsequent pulse energies. One of the machines used a $266 \mathrm{~nm}$ laser while the other was a $1064 \mathrm{~nm}$ laser. The $266 \mathrm{~nm}$ laser operated with a pulse energy of $25 \mathrm{~mJ}$ while the $1064 \mathrm{~nm}$ laser operated at $50 \mathrm{~mJ}$. A spectral range of 200-950 nm was collected at a firing rate of $2 \mathrm{~Hz}$. All collected spectra for the 266 $\mathrm{nm}$ laser were the result of an accumulation of 250 shots from a $0.75 \mathrm{~mm}$ line with the stage moving at a rate of $0.006 \mathrm{~mm} / \mathrm{s}$. Four lines were collected at different spots to represent the sample. The spectra from the $1064 \mathrm{~nm}$ laser were the result of 150 shots from a $0.75 \mathrm{~mm}$ line with the stage moving at $0.01 \mathrm{~mm} / \mathrm{s}$. As with the $266 \mathrm{~nm}$ laser, four lines were used to represent the sample.

Solutions of SmartWater ${ }^{\circledR}$ quality control (QC) samples were provided by SmartWater ${ }^{\circledR}$ Technologies along with a Tracer polymer blank solution that did not contain any of the elements used in the taggant. There were four QC samples that were examined for the current study. The Tracer solution is the primary tagging system that is used for 
marking valuable objects. It can be applied to most surfaces (such as fabrics, plastics, polymers, wood, papers, metals and ceramics), where it will solidify and create a layer that can later be recovered by law enforcement. The Tracer solution stands out from the other SmartWater ${ }^{\circledR}$ products by containing a larger concentration of the polymer used for solidification. The polymer makes up around $70 \%$ of the entire solution which allows it to create a thicker layer after application since less liquid will evaporate over time. The QC solution contains 27 elements consisting of $\mathrm{Ba}, \mathrm{Bi}, \mathrm{Ce}, \mathrm{Dy}, \mathrm{Er}, \mathrm{Eu}, \mathrm{Ga}, \mathrm{Gd}, \mathrm{Hf}, \mathrm{Ho}$, In, La, $\mathrm{Lu}, \mathrm{Nb}, \mathrm{Nd}, \mathrm{Pr}, \mathrm{Sm}, \mathrm{Tb}, \mathrm{Te}, \mathrm{Tm}, \mathrm{Y}, \mathrm{Yb}, \mathrm{Zr}, \mathrm{Mo}, \mathrm{Ge}, \mathrm{W}$, and Ta ranging in concentration from 26-126 ppm. Samples made using the Tracer QC solution were made by applying around $2 \mathrm{~mL}$ of the liquid onto a glass slide and left for 48 hours to solidify. Since the Tracer QC solution contains almost every metal used in SmartWater® products, it was the focus for the optimization and dilution experiments.

All spectra were saved as a .TDMS file and exported to the Aurora Data Analysis Software provided by Applied Spectra where the data could be processed. Because the sample discrimination was qualitative, the primary way to determine the presence or absence of an element was by assessing a peak's signal to noise ratio $(\mathrm{S} / \mathrm{N})$ which was calculated by using the following equation:

$$
\begin{aligned}
& \mathrm{S} / \mathrm{N}=(\text { intensity } \\
& \text { sample } \\
& \text { intensity } \\
& \text { intens }
\end{aligned}
$$

In order for a peak to not be considered noise, a threshold of 10 was set for the $\mathrm{S} / \mathrm{N}$ value. Any value at or above the threshold was thought to be an actual peak that could indicate the presence of an element. 


\section{POWER OUTPUT OPTIMIZATION}

The power output determines how powerful each laser shot is. Each laser needs to provide a sufficient amount of energy so that the analytes can become excited. Without excitation, no light will be produced and no results can be obtained. The power output of the laser is expressed as a percentage of its highest potential pulse energy. The $266 \mathrm{~nm}$ laser has a maximum power output of $25 \frac{\mathrm{mJ}}{\text { pulse }}$ and the $1066 \mathrm{~nm}$ laser has a maximum pulse energy of $50 \frac{\mathrm{mJ}}{\text { pulse }}$. While as little as $10 \%$ of the total pulse energy could penetrate the surface of the solidified Tracer QC solution, most of the atoms did not get enough energy to become excited until the power was turned up to around $80 \%$ for the $266 \mathrm{~nm}$ laser. As shown in Figure 2, a significant increase in the $\mathrm{S} / \mathrm{N}$ ratio for both barium and europium was observed when the power was increased until 90\%. While it is not known why, power outputs greater than $90 \%$ actually decreased the $\mathrm{S} / \mathrm{N}$ ratios. While the effect of the power output was greater for barium than it was for europium, both elements had their highest $\mathrm{S} / \mathrm{N}$ ratio at $90 \%$.

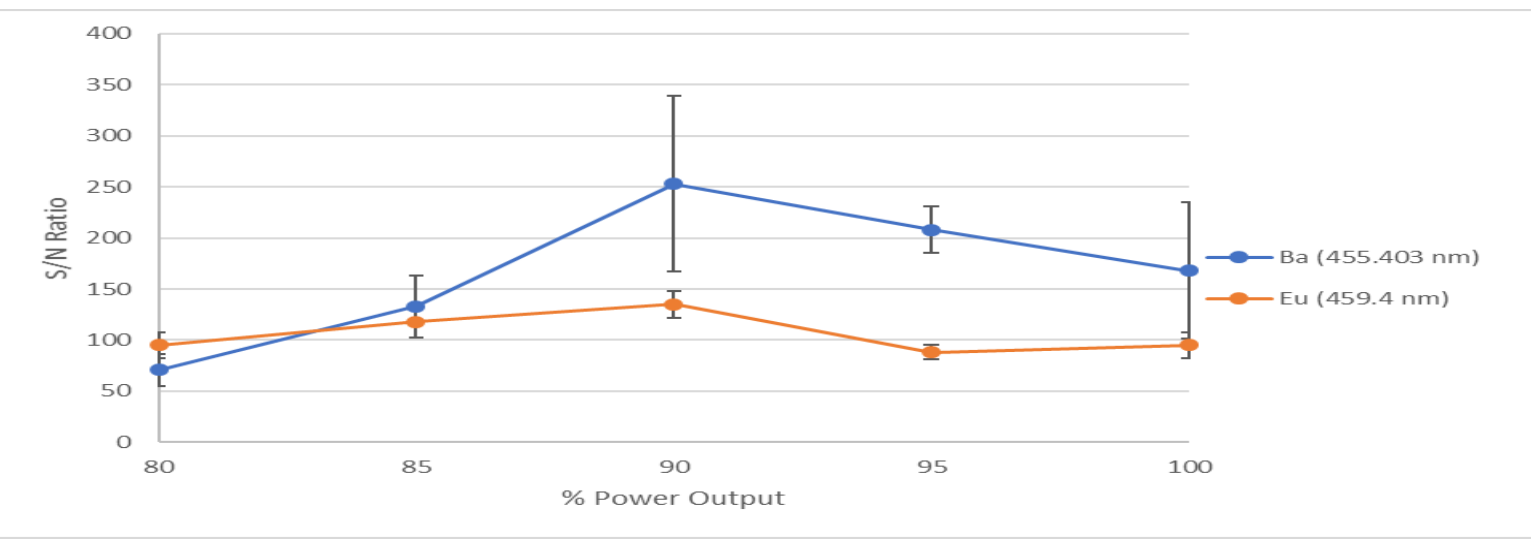

Figure 2: Power output effect on S/N for $266 \mathrm{~nm}$ laser. Collection parameters: $2 \mathrm{~Hz}$ fire rate, 0.7 $\mu$ s gate delay, $5.0 \mu$ s gate width, 50 gain, $6 \frac{\mu \mathrm{m}}{\mathrm{s}}$ stage speed, $100 \mu \mathrm{m}$ spot size, 4 lines that are each $0.25 \mathrm{~mm}$ apart and $0.75 \mathrm{~mm}$ long 
Since the $1064 \mathrm{~nm}$ laser has a higher energy pulse width than the $266 \mathrm{~nm}$ laser, elements could be detected with as little as $40 \%$ energy. However, as Figure 3 shows, while both $\mathrm{Eu}$ and $\mathrm{Ba}$ did not see much of an increase in their $\mathrm{S} / \mathrm{N}$ values between $40 \%$ and $100 \%$ energy, both $\mathrm{Yb}$ and La saw a consistent increase until around the power was between 70\% and $80 \%$. After 70\%, La saw a decline in its $\mathrm{S} / \mathrm{N}$ and $\mathrm{Yb}$ saw a slight decrease between $80 \%$ and $90 \%$ power followed by a sharp decline when the laser fired at $100 \%$ power. While there was not much of an increase, Eu did see its highest S/N value at $80 \%$ energy. Barium likewise had its highest S/N value at $80 \%$ energy. As such, further studies were performed with the laser pulsing at $80 \%$ of its total power.

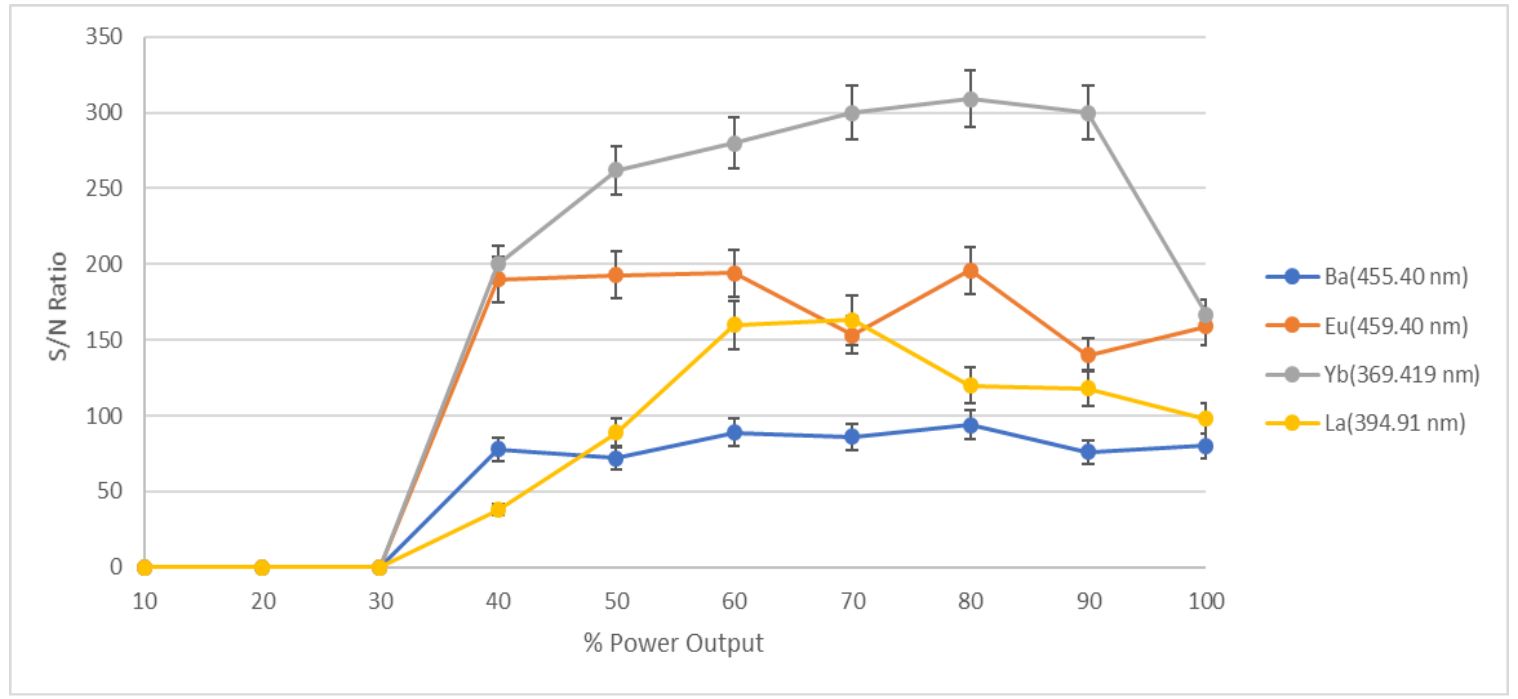

Figure 3: Power output effect on S/N for $1064 \mathrm{~nm}$ laser. Collection parameters: $2 \mathrm{~Hz}$ fire rate, $0.5 \mu$ s gate delay, $20 \mu$ s gate width, 50 gain, $10 \frac{\mu \mathrm{m}}{\mathrm{s}}$ stage speed, $175 \mu \mathrm{m}$ spot size, 4 lines that are each $0.5 \mathrm{~mm}$ apart and $0.75 \mathrm{~mm}$ long.

\section{GATE DELAY AND GATE WIDTH}

Timing is crucial when it comes to LIBS analysis. For information to be collected and interpreted, one must know the optimal gate delay, which is the time between when 
the laser is fired and when the spectrometer begins to collect data. Knowing where to set the gate delay is important because if the delay is set too short, the white light emitted directly after plasma formation will saturate the spectrometer and no intensities relating to the analytes will be collected. If the delay is too long, most of the emission form the elements of interest will be lost and the resulting spectrum will likely be just noise. The delay is also important since the timing will also affect how well one sees ionic and neutral species. After plasma formation, ionic elements will emit light before the neutral elements and will also decay quicker as well. Wavelengths corresponding to neutral elements are indicated with a "(I)" in front of their elemental symbols while wavelengths corresponding to ionic elements have a "(II)" in front of their elemental symbols.

For both the $266 \mathrm{~nm}$ and $1064 \mathrm{~nm}$ laser, gate delay studies were done by reducing the gate width to $0.5 \mu \mathrm{s}(500 \mathrm{~ns})$ and increasing it until one or more elements could no longer be observed. Both ionic and neutral species were observed during analysis to see how each was affected and if any patterns could be recognized. With the $266 \mathrm{~nm}$ laser, Eu and Mo were the observed neutral species while $\mathrm{Yb}$ and $\mathrm{La}$ were the examined ionic elements. While there was not much of a difference between a gate delay of 0.5 and $2.0 \mu \mathrm{s}$ for Eu and Mo, both $\mathrm{Yb}$ and La saw a consistent decline in their S/N ratios (Figure 4). When the gate delay was set to $2.5 \mu \mathrm{s}$, only Eu could still be observed. Thus, it was determined that $0.5 \mu \mathrm{s}$ was the optimal gate width for the $266 \mathrm{~nm}$ laser. 


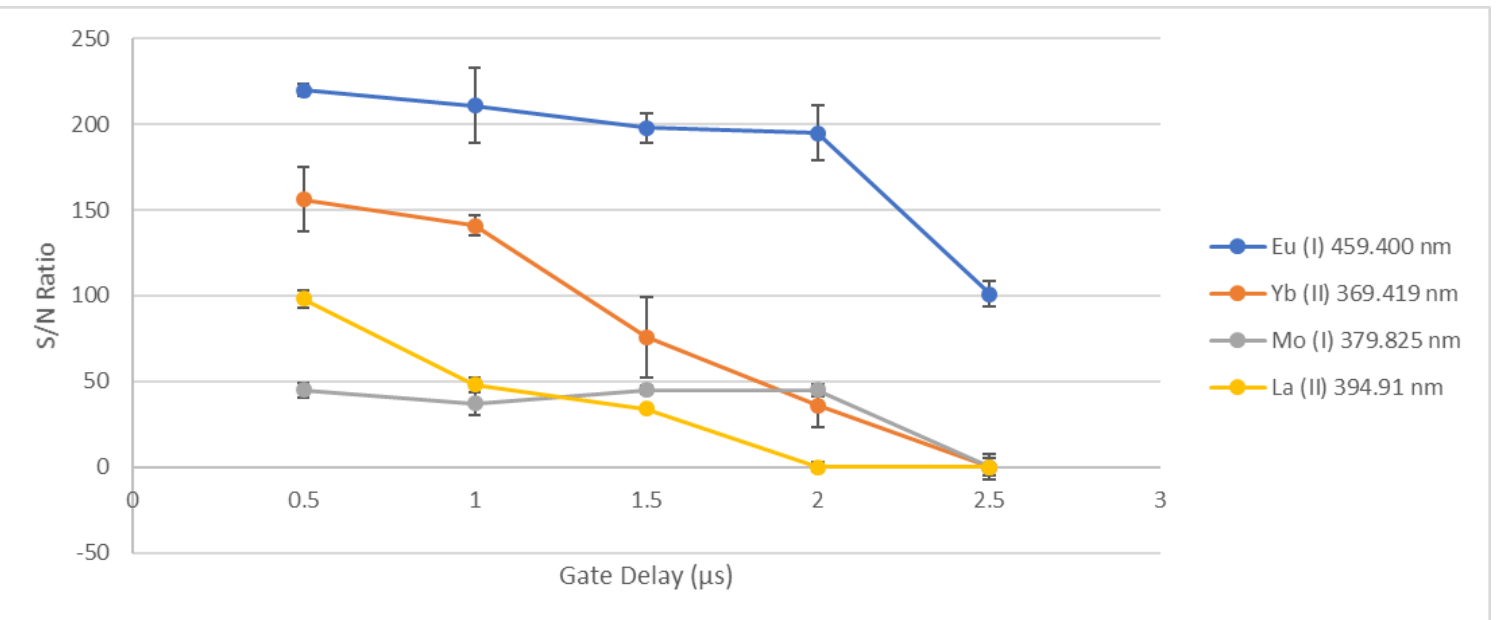

Figure 4: Gate Delay effect on S/N for the $266 \mathrm{~nm}$ laser. Collection parameters: $90 \%$ energy output, $2 \mathrm{~Hz}$ fire rate, $5.0 \mu$ s gate width, 50 gain, $6 \frac{\mu \mathrm{m}}{\mathrm{s}}$ stage speed, $100 \mu \mathrm{m}$ spot size, 4 lines that are each $0.25 \mathrm{~mm}$ apart and $0.75 \mathrm{~mm}$ long.

Compared to its counterpart, the $1064 \mathrm{~nm}$ laser showed greater persistency with its observed elements. Instead of losing three of the four elements after a gate delay of just 2.5 $\mu \mathrm{s}$, all elements were observed when the delay was set as high as $15 \mu \mathrm{s}$. When set higher both La and Y could no longer be distinguished in the spectrum. In fact, it took a gate delay of between 5 to $7 \mu$ s to observe any consistent decrease in $\mathrm{S} / \mathrm{N}$ ratios for the ionic elements (Yb, La, and Y) (Figure 5). With the neutral elements (Ba, Eu, and Mo), there appeared to be an increase in $\mathrm{S} / \mathrm{N}$ ratios until the gate delay was set to $3.5 \mu \mathrm{s}$. After that, the $\mathrm{S} / \mathrm{N}$ ratios for the neutral species decreased and later remained relatively unchanged. Since the best results were obtained for the neutral species at $3.5 \mu$ s and there was little to no change for the ionic elements until at least $5 \mu \mathrm{s}$, the optimal gate delay was set to $3.5 \mu \mathrm{s}$ for the 1064 nm laser. 

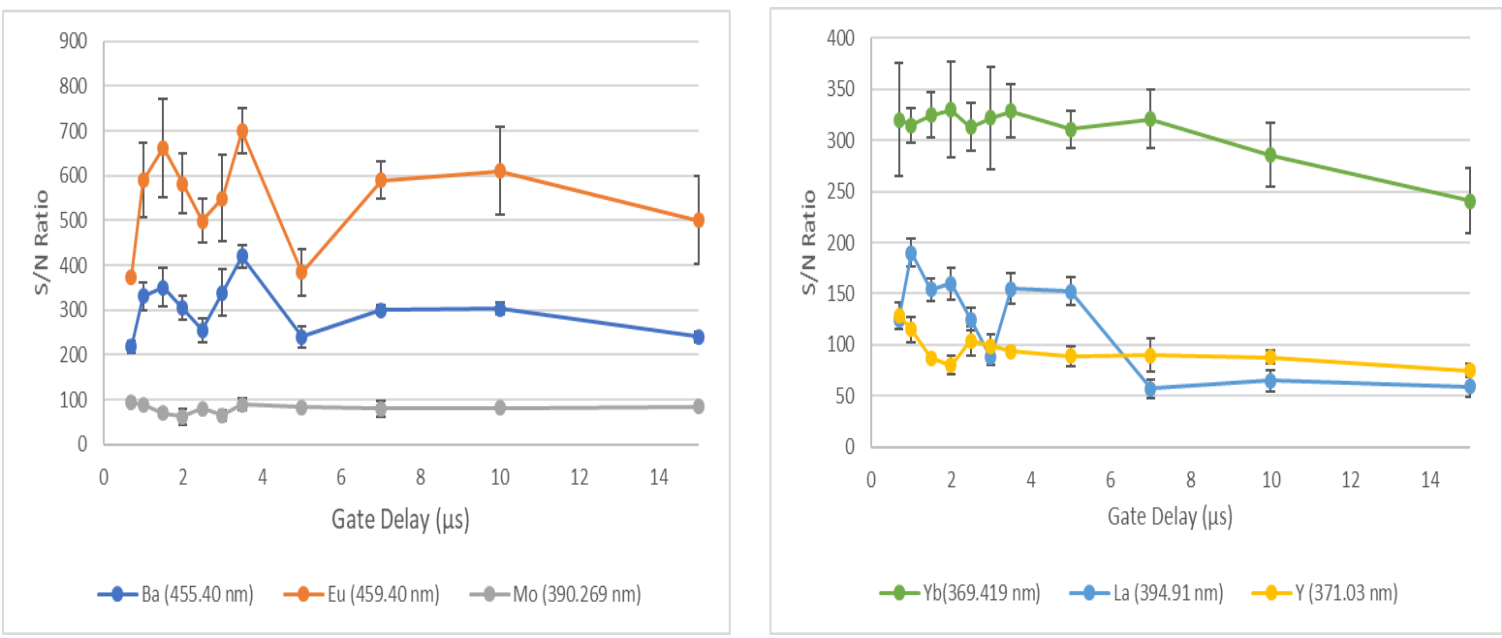

Figure 5: Gate Delay effect on $\mathrm{S} / \mathrm{N}$ for the $1064 \mathrm{~nm}$ laser for both ionic (right) and neutral (left) elements. Collection parameters: $80 \%$ energy output, $2 \mathrm{~Hz}$ fire rate, $20 \mu \mathrm{s}$ gate width, 50 gain, $10 \frac{\mu \mathrm{m}}{\mathrm{s}}$ stage speed, $175 \mu \mathrm{m}$ spot size, 4 lines that are each $0.5 \mathrm{~mm}$ apart and $0.75 \mathrm{~mm}$ long.

Gate width is the amount of time the detector remains open and collects the light given from a plasma. The longer the gate width, the longer the detector picks up signal and, in theory, the higher the intensities of the peaks will be up to a certain point. Knowing how long to keep the detector open before the $\mathrm{S} / \mathrm{N}$ ratios reach their maximum limit is essential during optimization experiments. As with the gate delay experiments, both ionic and neutral elements were observed since they have different timing when it comes to when their light is emitted and how long it is emitted for. Starting at $3 \mu \mathrm{s}$, the gate width was increased until either maximum $\mathrm{S} / \mathrm{N}$ ratios were observed or until the ratios level off. With the $266 \mathrm{~nm}$ laser, every observed element reached a maximum $\mathrm{S} / \mathrm{N}$ ratio at $20 \mu \mathrm{s}$ with a slight decrease at any time longer than that (Figure 6). The decrease in the signal-to-noise ratios could be caused by the plasma decaying past $20 \mu$ s which would mean that no further emissions could be collected from the plasma. Whether this is the case or not, the optimal width for the $266 \mathrm{~nm}$ laser was set to $20 \mu \mathrm{s}$. 


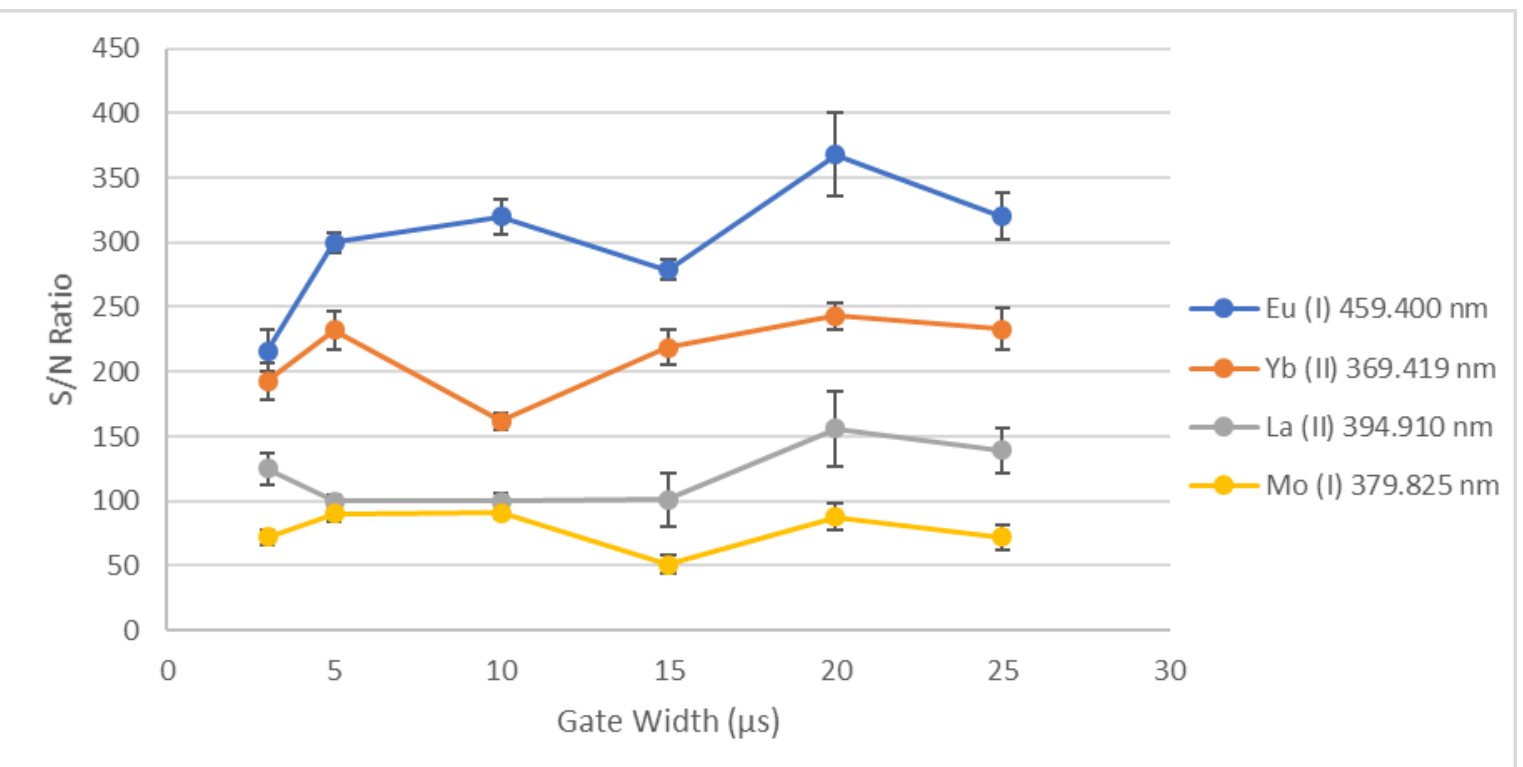

Figure 6: Gate width effect on S/N on $266 \mathrm{~nm}$ laser. Collection parameters: $90 \%$ energy output, $2 \mathrm{~Hz}$ fire rate, $0.5 \mu$ s gate delay, 50 gain, $6 \frac{\mu \mathrm{m}}{\mathrm{s}}$ stage speed, $100 \mu \mathrm{m}$ spot size, 4 lines that are each $0.25 \mathrm{~mm}$ apart and $0.75 \mathrm{~mm}$ long

When performing the same experiment on the $1064 \mathrm{~nm}$ laser, every element saw an increase in their respective $\mathrm{S} / \mathrm{N}$ ratio until the gate width was set to $15 \mu$ s (Figure 7 ). The ionic species then had a consistent decrease in their $\mathrm{S} / \mathrm{N}$ ratios followed by their values levelling off. The neutral elements appeared to have their $\mathrm{S} / \mathrm{N}$ ratios level off after $15 \mu \mathrm{s}$, with both $\mathrm{Eu}$ and $\mathrm{Ba}$ experiencing a sharp decline when the width was set to $100 \mu \mathrm{s}$, meaning that the optimal gate width was set to $15 \mu$ s for the $1064 \mathrm{~nm}$ laser. 


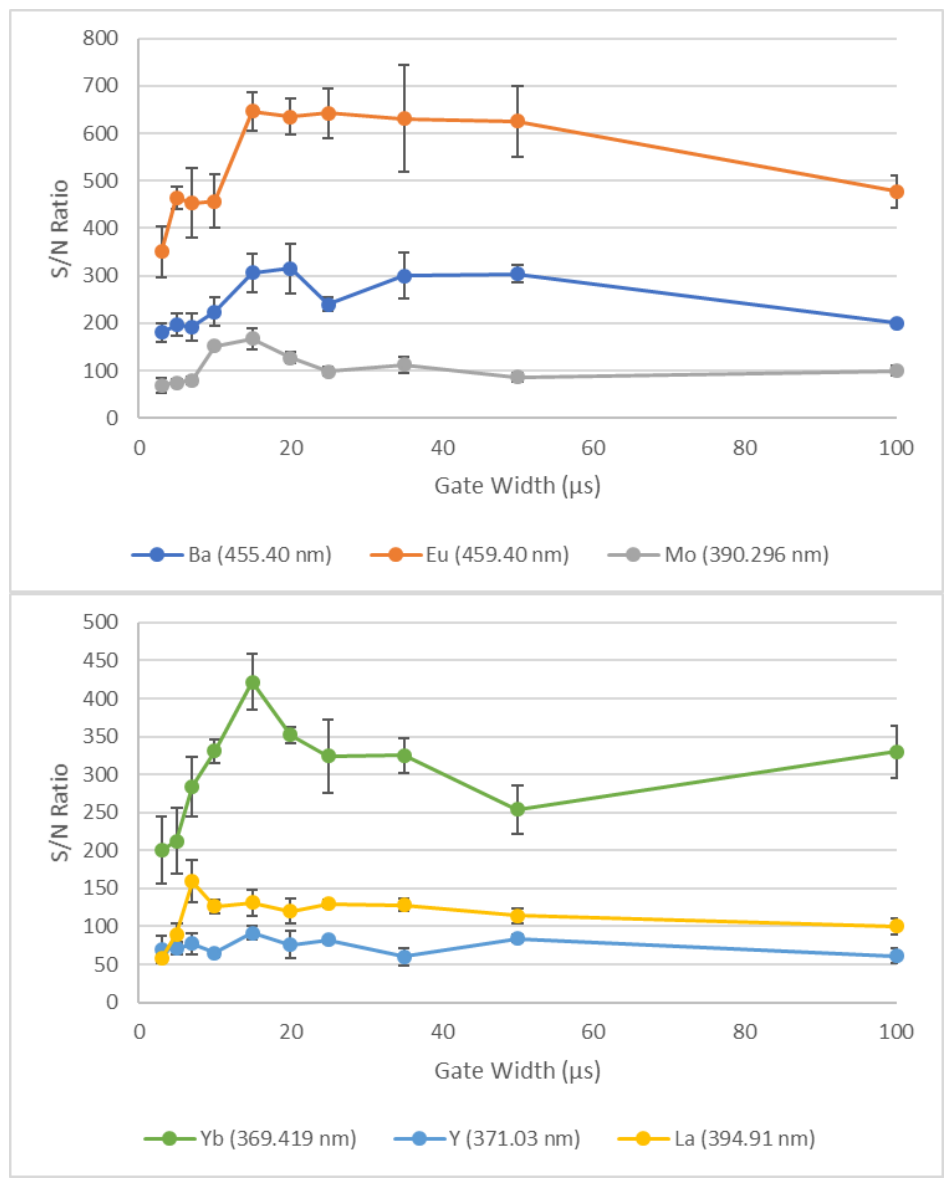

Figure 7: Gate width effect on S/N on $1064 \mathrm{~nm}$ laser for ionic (bottom) and neutral (top) elements. Collection parameters: $80 \%$ energy output, $2 \mathrm{~Hz}$ fire rate, $3.5 \mu$ s gate delay, 50 gain, $10 \frac{\mu \mathrm{m}}{\mathrm{s}}$ stage speed, $175 \mu \mathrm{m}$ spot size, 4 lines that are each $0.5 \mathrm{~mm}$ apart and $0.75 \mathrm{~mm}$ long

\section{SPOT SIZE}

The spot size of the laser refers to the diameter of the beam that fires on the surface of a sample. Larger spot sizes should lead to more ablation since each laser shot covers a wider area. In theory, more ablation should lead to an increase in signal intensities since more sample ablation means increased emissions. There are seven different options for laser spot sizes that were equipped with the $266 \mathrm{~nm}$ laser. These sizes include a laser beam diameter of $60,75,85,100,120,150$, and $200 \mu \mathrm{m}$. Every spot size was tested and, as was 
the case with the previous parameter studies, both ionic and neutral elements were tested to see if any discernable patterns could be observed. Figure 8 shows the results from the experiment. While every studied element could be observed at every spot size, there are a few notable patterns. Every element had its peak $\mathrm{S} / \mathrm{N}$ value at a spot size of either 85 or $100 \mu \mathrm{m}$. Between 100 and $200 \mu \mathrm{m}$, there was a consistent decrease in the $\mathrm{S} / \mathrm{N}$ ratios. It appeared that the further away one got from the $100 \mu \mathrm{m}$ spot size, the lower the signal to noise values were. While all spot sizes produced competent results, based on the signal to noise ratios of the studied elements, the optimal spot sizes are those between 85 and 100 $\mu \mathrm{m}$ and, as such, future experiments were run at a spot size of $100 \mu \mathrm{m}$ when using the 266 nm laser.

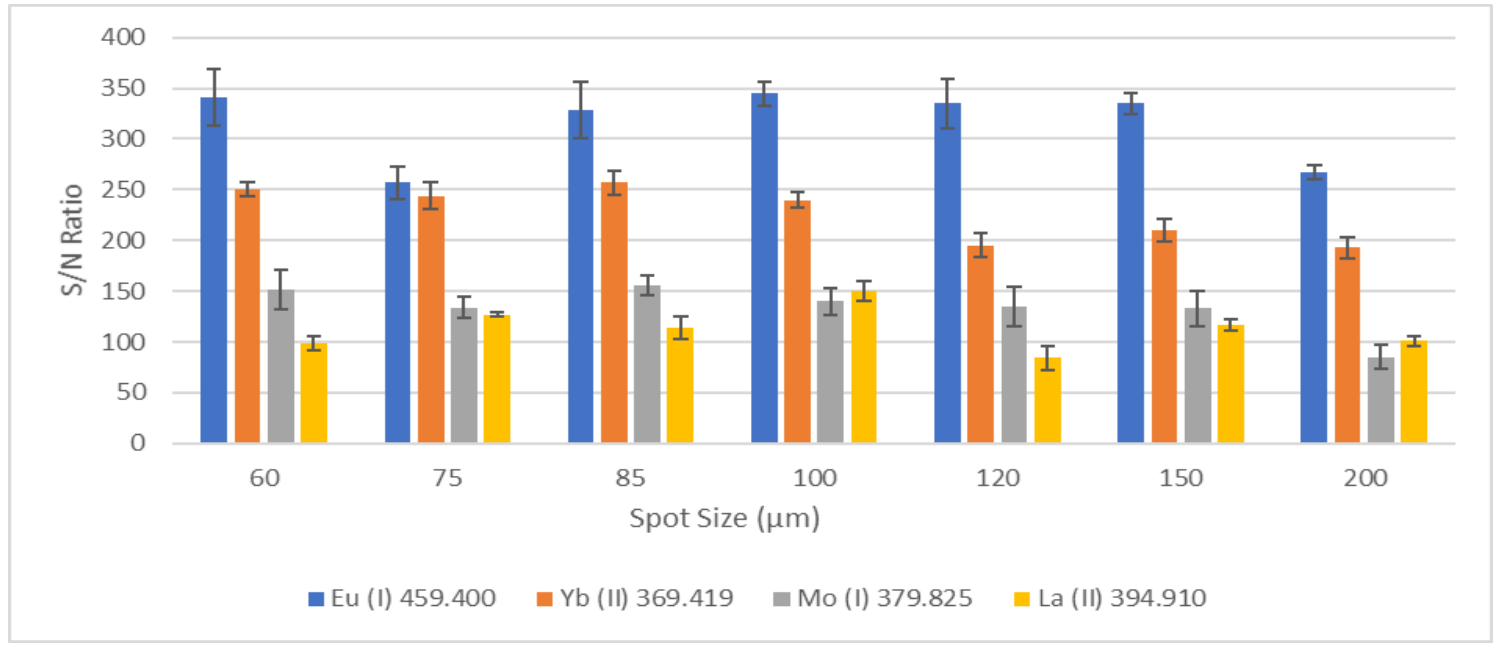

Figure 8: Spot size effect on $\mathrm{S} / \mathrm{N}$ ratios for the $266 \mathrm{~nm}$ laser. Collection parameters: $90 \%$ energy output, $2 \mathrm{~Hz}$ fire rate, $0.5 \mu$ s gate delay, $20 \mu \mathrm{s}$ gate width, 50 gain, $6 \frac{\mu \mathrm{m}}{\mathrm{s}}$ stage speed, 4 lines that are each $0.25 \mathrm{~mm}$ apart and $0.75 \mathrm{~mm}$ long. 


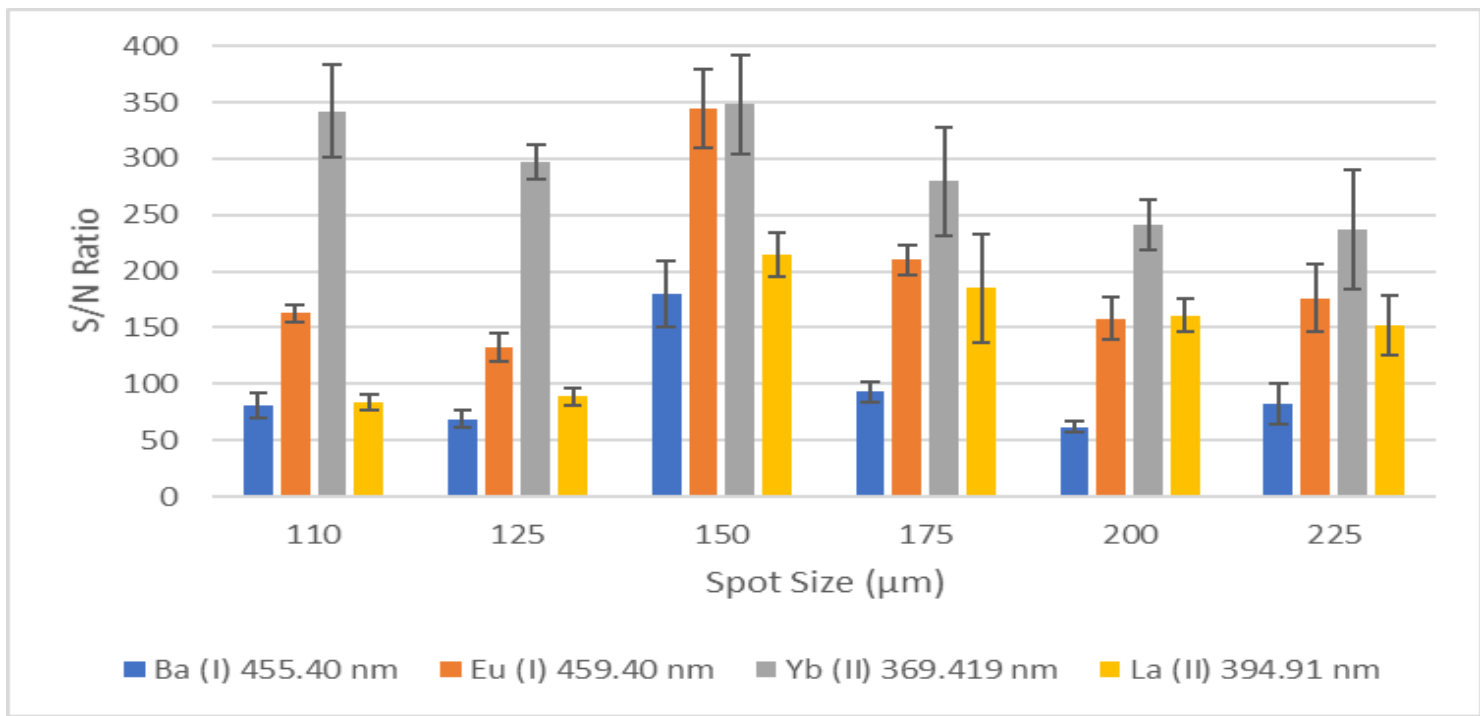

Figure 9: Spot size effect on $\mathrm{S} / \mathrm{N}$ ratios for the $1064 \mathrm{~nm}$ laser. Collection parameters: $80 \%$ energy output, $2 \mathrm{~Hz}$ fire rate, $3.5 \mu$ s gate delay, $15 \mu$ sate width, 50 gain, $10 \frac{\mu \mathrm{m}}{\mathrm{s}}$ stage speed, 4 lines that are each $0.50 \mathrm{~mm}$ apart and $0.75 \mathrm{~mm}$ long.

While the $1064 \mathrm{~nm}$ laser also had different options for spot size similar to the 266 nm laser, its choices were limited to a range between 110 and $225 \mu \mathrm{m}$ instead of between 60 and $200 \mu \mathrm{m}$. There was a more noticeable effect the spot size had on the results with the $1064 \mathrm{~nm}$ laser compared to the $266 \mathrm{~nm}$ laser. As is shown in Figure 9, every element had its peak $\mathrm{S} / \mathrm{N}$ value at a spot size of $150 \mu \mathrm{m}$. The further away the spot size got from 150 $\mu \mathrm{m}$, the worse the results became. While any of the spot size options would produce good results, there is a far more noticeable difference in $\mathrm{S} / \mathrm{N}$ ratios between the optimal spot size and all other options despite the idea that larger spot sizes would lead to higher intensities due to an increase in area ablation.

\section{AIR VS ARGON ATMOSPHERE}

Studies done using LIBS have shown that having an argon atmosphere in the sampling container as opposed to air can lead to higher intensities which, in turn, can 
increase the $\mathrm{S} / \mathrm{N}$ ratios of the analytes in the resulting spectrum [6]. Oxygen in the air supposedly quenches the light produced by the emissions which reduces not only the intensity of the light but could also lead to faster degradation [6]. While Wise reported that having an atmosphere of argon did not make much of a difference when it came to the signal intensities of SmartWater ${ }^{\circledR}$ elements, it was nonetheless still investigated during the optimization experiments because of previous success found in other LIBS studies.

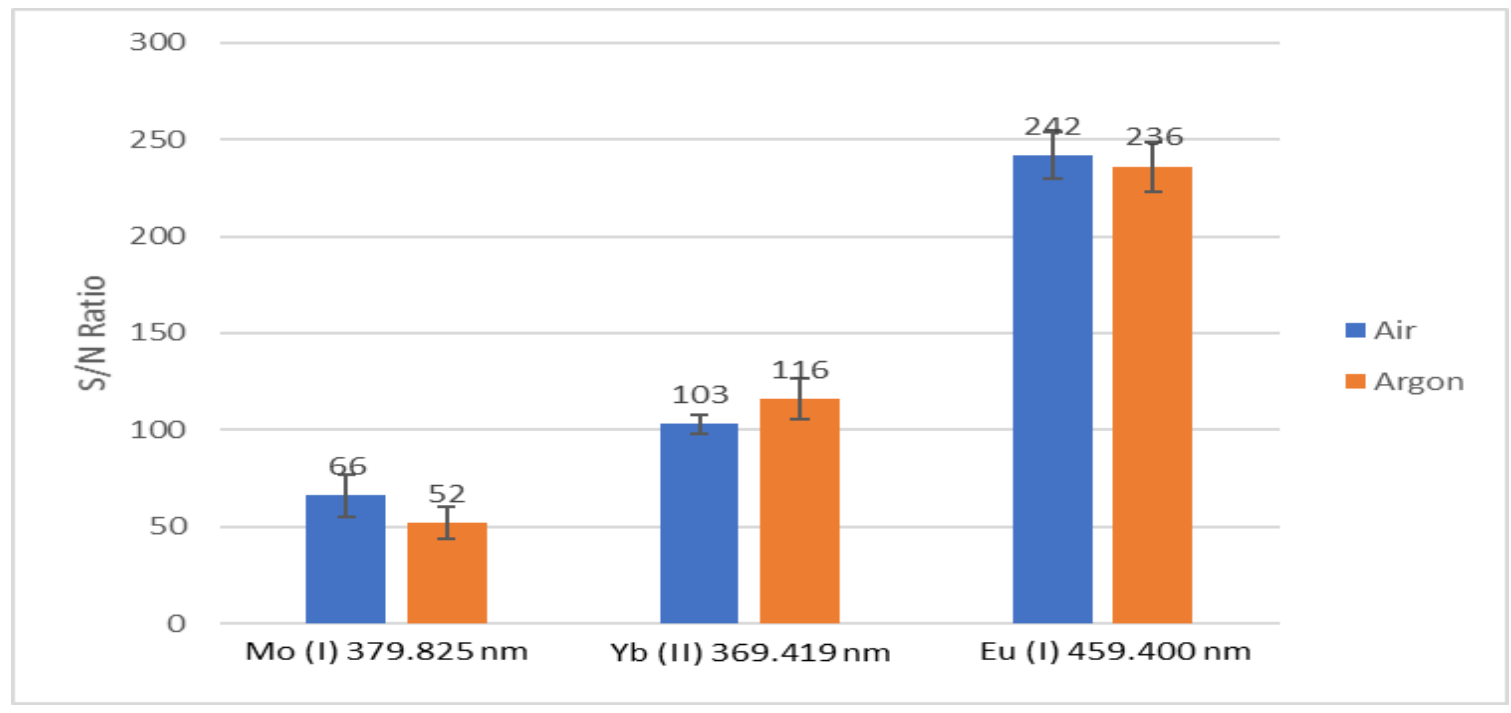

Figure 10: S/N ratios for europium, ytterbium, and molybdenum in air and in an argon environment. Collection parameters: $90 \%$ energy output, $2 \mathrm{~Hz}$ fire rate, $0.5 \mu$ s gate delay, 5.0 $\mu$ s width, 50 gain, $6 \frac{\mu \mathrm{m}}{\mathrm{s}}$ stage speed, $100 \mu \mathrm{m}$ spot size, 4 lines that are each $0.25 \mathrm{~mm}$ apart and $0.75 \mathrm{~mm}$ long

The $266 \mathrm{~nm}$ laser was run in an atmosphere air and argon. A Tracer QC solution was first analyzed without purging the sampling chamber, which corresponds to an atmosphere of air, and later was purged with argon gas, which displaces all the air in the chamber and replaces it with argon gas from a tank connected to the laser. Three elements were investigated as part of this experiment including europium (Eu), ytterbium (Yb), and molybdenum (Mo). The results from Figure 10 show that, as was documented in Wise's 
case, there did not appear to be much of a difference in the $\mathrm{S} / \mathrm{N}$ ratios for the observed elements. While there was a slight increase in ytterbium's $\mathrm{S} / \mathrm{N}$ ratio, both $\mathrm{Eu}$ and Mo actually saw a decrease in their corresponding values. As was speculated in Wise's paper, the lower $\mathrm{S} / \mathrm{N}$ ratios could be a result of an increase in the background signals which comes from the entire continuum not decaying as quickly [6]. Since the $\mathrm{S} / \mathrm{N}$ ratios were similar in both atmospheres, future experiments were conducted in air.

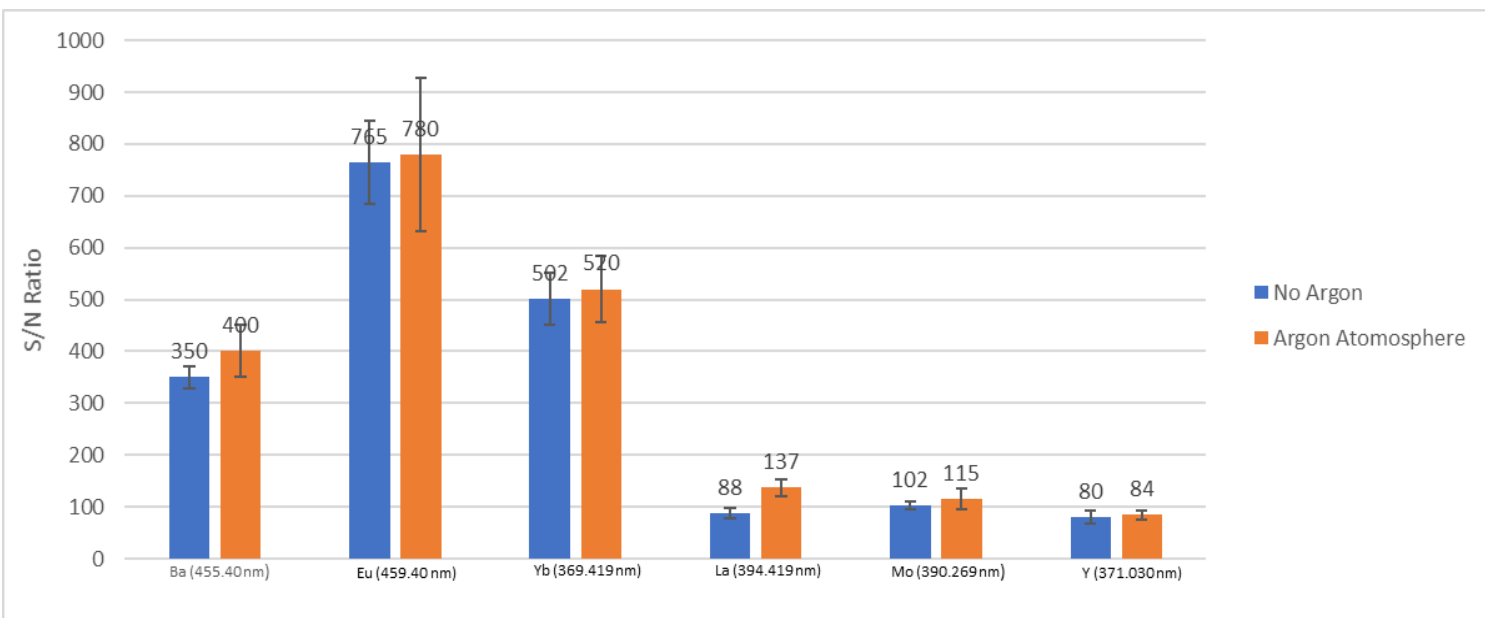

Figure 11: Argon vs Air environment effect on results from $1064 \mathrm{~nm}$ laser. Collection parameters: $80 \%$ energy output, $2 \mathrm{~Hz}$ fire rate, $3.5 \mu$ s gate delay, $15 \mu$ s width, 50 gain, $10 \frac{\mu \mathrm{m}}{\mathrm{s}}$ stage speed, $150 \mu \mathrm{m}$ spot size, 4 lines that are each $0.5 \mathrm{~mm}$ apart and $0.75 \mathrm{~mm}$ long

The same experiment was performed using the $1064 \mathrm{~nm}$ laser. As with the $266 \mathrm{~nm}$ laser, the Tracer QC sample was analyzed in an environment containing air (without purging the sample chamber) as well as argon (when the sample chamber was purged with argon gas). For this experiment, five elements were analyzed including $\mathrm{Ba}, \mathrm{Eu}, \mathrm{Yb}, \mathrm{La}$, Mo, and Y. Unlike the $266 \mathrm{~nm}$ laser, the atmosphere of argon did make an impact on the $\mathrm{S} / \mathrm{N}$ ratios of the observed elements. As is shown in Figure 11, the increase in $\mathrm{S} / \mathrm{N}$ ratios ranged from $2 \%$ with Eu to $56 \%$ with La. While there was a wide variability in how much the argon atmosphere affected the results, there was nonetheless still an increase in the S/N 
for every element that was studied. As such, further experiments using the $1064 \mathrm{~nm}$ laser were conducted using an argon atmosphere.

\section{STAGE DISCPLACEMENT}

While most LIBS experiments are performed by focusing on the surface of a sample, it is also possible with some samples to change the height of the stage in order to modify what the camera is focused on. SmartWater ${ }^{\circledR}$ Tracer QC samples, once solidified on a glass slide, can form a layer that is around one millimeter thick. While focusing the laser on the surface produces adequate results, changing the stage height so the laser focuses inside the sample as opposed to focusing just on the surface can lead to more ablation and plasma formation which would produce higher intensities from the analytes. The laser was focused on the surface of a glass slide that contained the Tracer QC SmartWater ${ }^{\circledR}$ solution and the z-direction (stage height) of the chamber was changed until the peak(s) being observed could no longer be seen in the resulting spectrum.

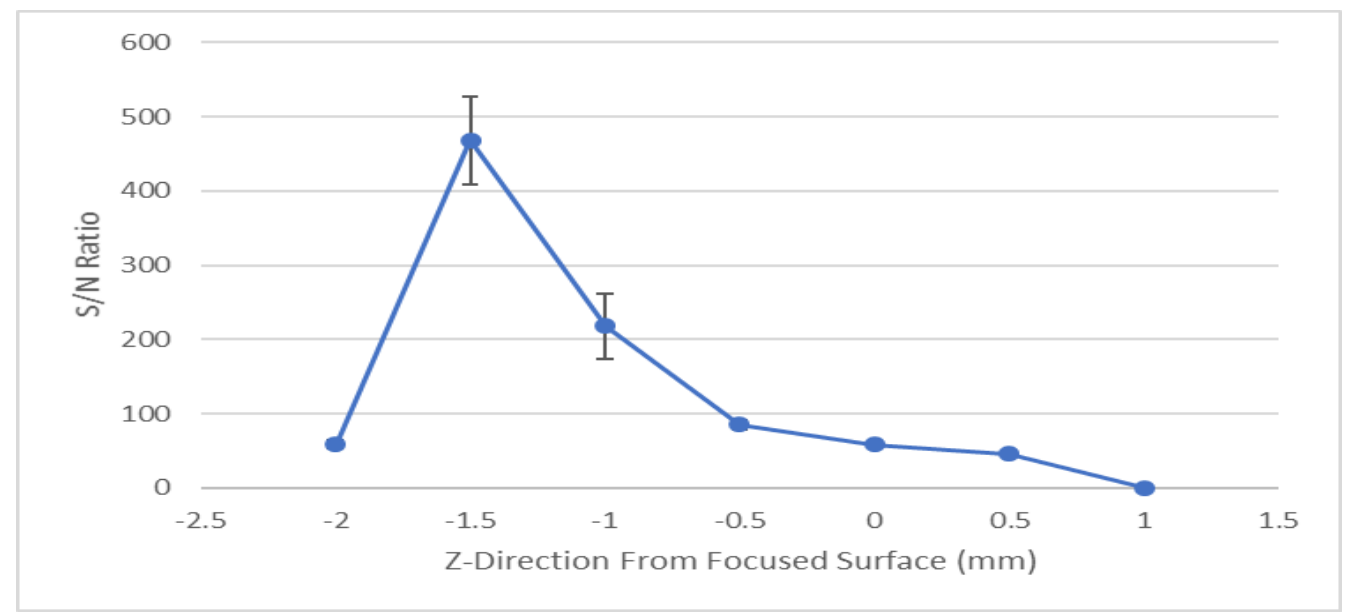

Figure 12: Surface defocusing effect on $\mathrm{S} / \mathrm{N}$ for Ba at $455.403 \mathrm{~nm}$ using $266 \mathrm{~nm}$ laser. Collection parameters: $90 \%$ energy, $2 \mathrm{~Hz}$ fire rate, $0.5 \mu$ s gate delay, $20 \mu \mathrm{s}$ gate width, 50 gain, $6 \frac{\mu \mathrm{m}}{\mathrm{s}}$ stage speed, $150 \mu \mathrm{m}$ spot size, 4 lines that are each 0.25 $\mathrm{mm}$ apart and $0.75 \mathrm{~mm}$ long. 
When performing the experiment on the $266 \mathrm{~nm}$ laser, the stage was raised and lowered in increments of $0.5 \mathrm{~mm}$ and barium was the element that was chosen to be observed. Since raising the stage meant that the laser was focused inside the sample, it was expected that not only would more sample be ablated but also that the $\mathrm{S} / \mathrm{N}$ ratios would be higher compared to when the laser was focused on the surface of the sample. However, as Figure 12 shows, while raising the stage significantly decreased the signal to noise ratio of the peak, lowering the stage actually had the opposite effect until it was dropped $1.5 \mathrm{~mm}$ below the focused surface. Lowering the stage more than $2.0 \mathrm{~mm}$ and raising it $1.0 \mathrm{~mm}$ from where it was focused on the surface lead to barium no longer being observed.

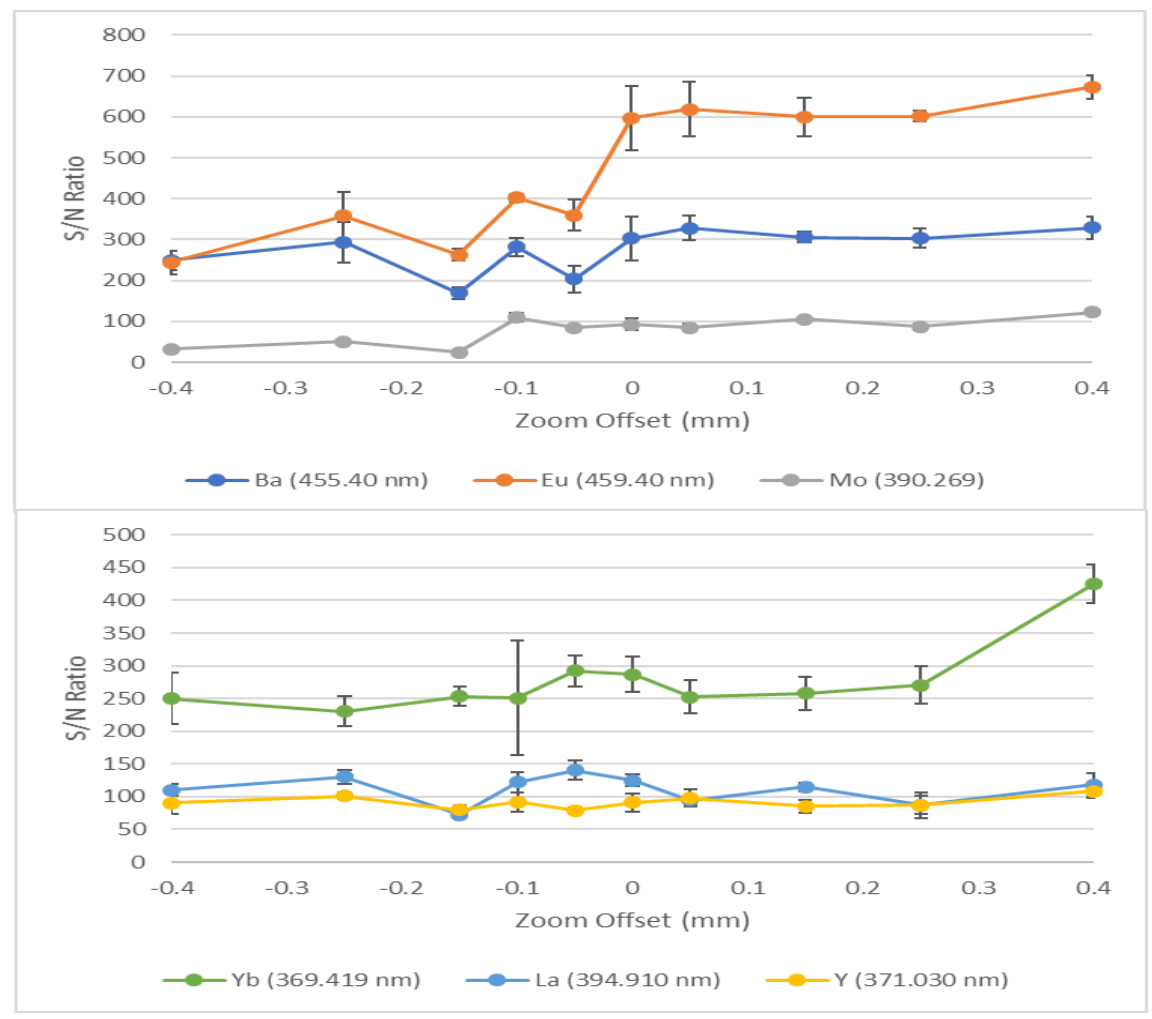

Figure 13: Surface defocusing effect on S/N ratios using $1064 \mathrm{~nm}$ laser for ionic (bottom) and neutral (top) elements. Collection parameters: $80 \%$ energy, $2 \mathrm{~Hz}$ fire rate, $3.5 \mu$ s gate delay, $15 \mu$ s gate width, 50 gain, $10 \frac{\mu \mathrm{m}}{\mathrm{s}}$ stage speed, $150 \mu \mathrm{m}$ spot size, 4 lines that are each $0.5 \mathrm{~mm}$ apart and $0.75 \mathrm{~mm}$ long. 
When performing the same experiment using the $1064 \mathrm{~nm}$ laser, a few notable events occurred. When lowering the stage by $0.5 \mathrm{~mm}$ from the QC's sample surface, none of the observed elements ( $\mathrm{Ba}, \mathrm{Eu}, \mathrm{Mo}, \mathrm{Yb}, \mathrm{La}$, and $\mathrm{Y}$ in this case) could be observed. Raising the stage by $0.5 \mathrm{~mm}$ lead to the laser being focused on the surface below the sample layer and glass would be ablated along with the sample, causing many interfering wavelengths that often overlapped with the elements being observed. The experiment was changed so that instead of lowering and raising the stage in increments of $0.5 \mathrm{~mm}$, it was instead changed in smaller increments. As Figure 13 shows, lowering the stage significantly reduced the $\mathrm{S} / \mathrm{N}$ ratios for $\mathrm{Ba}, \mathrm{Eu}$, and Mo while not seeming to make much of an impact on $\mathrm{Yb}, \mathrm{La}$, and $\mathrm{Y}$. However, while raising the stage by up to $0.25 \mathrm{~mm}$ did not appear to have make any significant difference on any of the results, as soon as the stage was raised to $0.4 \mathrm{~mm}$, almost every element saw a large increase in their respective $\mathrm{S} / \mathrm{N}$ ratios. Raising the stage anymore than $0.4 \mathrm{~mm}$ lead to glass being ablated and interfering with the results.

\section{OPTIMIZED RESULTS OF THE 266 NM AND 1064 NM LASER}

Once both lasers were optimized, a final analysis was performed using their respective optimal parameters. The Tracer QC solution was analyzed since it includes the most elements in its formulation. A list of elements along with the respective wavelength that gave the highest $\mathrm{S} / \mathrm{N}$ ratio for each element can be seen in Tables 1 and 2. Identified elements had at least one fully resolved peak with no overlap with other elements or other interferences. Overall, the $266 \mathrm{~nm}$ laser was able to identify 18 of the 27 elements used in the Tracer QC solution with $\mathrm{S} / \mathrm{N}$ ratios ranging from 30-574. Nine elements in total could 
not be detected at all at given their respective concentration in the Tracer QC sample including Bi, Ge, Hf, Pr, Ta, Tb, Te, W, and Zr. While some of these elements, such as Bi, Pr, Hf, and Zr have been identified by Wise when he used LIBS to identify SmartWater ${ }^{\circledR}$ elements, they could only be seen when their concentrations were at least double what they are in current SmartWater ${ }^{\circledR}$ solutions. The other unidentified elements have their strongest emission peaks between 200 and $300 \mathrm{~nm}$ which is important since the Andor iStar spectrometer appeared to have difficulty detecting much light at that range.

Table 1: Elements detected using $266 \mathrm{~nm}$ laser along with their respective wavelengths used for identification and their concentration in the Tracer QC solution.

\begin{tabular}{|c|c|c|c|}
\hline Element & $\begin{array}{c}\text { Wavelength } \\
\text { (nm) }\end{array}$ & $\begin{array}{c}\text { Concentration } \\
\text { (ppm) }\end{array}$ & $\begin{array}{c}\text { S/N } \\
\text { Ratio }\end{array}$ \\
\hline $\mathrm{Ba}(\mathrm{I})$ & 455.403 & 126 & 122 \\
\hline $\mathrm{Ce}$ (II) & 418.660 & 38 & 117 \\
\hline Dy (II) & 353.170 & 53 & 46 \\
\hline Er (II) & 390.631 & 54 & 135 \\
\hline $\mathrm{Eu}(\mathrm{I})$ & 459.403 & 68 & 574 \\
\hline $\mathrm{Ga}(\mathrm{I})$ & 417.204 & 27 & 36 \\
\hline Gd (II) & 336.223 & 52 & 56 \\
\hline Ho (II) & 389.102 & 54 & 162 \\
\hline In (I) & 451.131 & 41 & 103 \\
\hline $\mathrm{La}$ (II) & 394.910 & 47 & 83 \\
\hline $\mathrm{Lu}(\mathrm{II})$ & 355.444 & 56 & 53 \\
\hline Mo (I) & 379.825 & 56 & 139 \\
\hline $\mathrm{Nb}(\mathrm{II})$ & 309.418 & 99 & 42 \\
\hline Nd (II) & 401.225 & 49 & 30 \\
\hline $\mathrm{Sm}$ (II) & 359.260 & 50 & 74 \\
\hline $\operatorname{Tm}(\mathrm{I})$ & 409.419 & 55 & 34 \\
\hline Y (II) & 371.030 & 33 & 89 \\
\hline $\mathrm{Yb}(\mathrm{II})$ & 369.419 & 56 & 288 \\
\hline
\end{tabular}


Table 2: Elements detected using 1064 nm laser along with their respective wavelengths used for identification and their concentration in the Tracer QC solution.

\begin{tabular}{|c|c|c|c|}
\hline Element & $\begin{array}{l}\text { Wavelength } \\
(\mathrm{nm})\end{array}$ & $\begin{array}{c}\text { Concentration } \\
(\mathrm{ppm})\end{array}$ & $\begin{array}{l}\text { S/N } \\
\text { Ratio }\end{array}$ \\
\hline $\mathrm{Ba}(\mathrm{I})$ & 455.403 & 126 & 260 \\
\hline $\mathrm{Ce}$ (II) & 418.660 & 38 & 75 \\
\hline Dy (II) & 353.170 & 53 & 135 \\
\hline $\mathrm{Er}$ (II) & 390.631 & 54 & 131 \\
\hline $\mathrm{Eu}(\mathrm{I})$ & 459.403 & 68 & 639 \\
\hline $\mathrm{Ga}(\mathrm{I})$ & 417.204 & 27 & 180 \\
\hline Gd (II) & 336.223 & 52 & 38 \\
\hline Ho (II) & 389.102 & 54 & 74 \\
\hline In (I) & 451.131 & 41 & 308 \\
\hline $\mathrm{La}$ (II) & 394.910 & 47 & 71 \\
\hline $\mathrm{Lu}(\mathrm{II})$ & 355.444 & 56 & 161 \\
\hline Mo (I) & 379.825 & 56 & 194 \\
\hline $\mathrm{Nb}$ (II) & 309.418 & 99 & 200 \\
\hline Nd (II) & 401.225 & 49 & 85 \\
\hline $\operatorname{Pr}(\mathrm{I})$ & 469.577 & 64 & 99 \\
\hline Sm (II) & 359.260 & 50 & 110 \\
\hline $\operatorname{Tm}(\mathrm{I})$ & 409.419 & 55 & 88 \\
\hline Y (II) & 371.030 & 33 & 50 \\
\hline $\mathrm{Yb}$ (II) & 369.419 & 56 & 498 \\
\hline
\end{tabular}

The $1064 \mathrm{~nm}$ laser was able to identify all of the elements that the $266 \mathrm{~nm}$ laser could along with praseodymium meaning that the $1064 \mathrm{~nm}$ laser could determine up to 19 elements, while the $266 \mathrm{~nm}$ laser could only find up to 18 . In addition, every element except $\mathrm{Ce}, \mathrm{Er}, \mathrm{Gd}, \mathrm{Ho}, \mathrm{In}, \mathrm{La}$, and Y had a significantly higher S/N ratio when the $1064 \mathrm{~nm}$ laser was used. Elements with higher $\mathrm{S} / \mathrm{N}$ ratios on the $266 \mathrm{~nm}$ laser had a value between 1.03 and 2.16 times higher than their counterpart on the $1064 \mathrm{~nm}$ laser. By contrast, the 11 elements that had a higher $\mathrm{S} / \mathrm{N}$ ratio on the $1064 \mathrm{~nm}$ laser had values that were anywhere 
between 1.11 and 5 times higher than when they were found using $266 \mathrm{~nm}$ laser. Since the $1064 \mathrm{~nm}$ laser could not only identify more elements but could also see most of the elements better than the $266 \mathrm{~nm}$ laser could, it seems that it is better overall for identifying the taggants used in SmartWater ${ }^{\circledR}$ samples. 


\section{CHAPTER 4: DILUTIONS AND ANALYSIS OF DIFFERENT SOLUTIONS}

\section{EFFECT OF DILUTIONS ON 266 NM LASER RESULTS}

Once it was determined how well LIBS worked with the undiluted quality control samples, experiments were performed that mimicked more "real world" scenarios. For example, when SmartWater ${ }^{\circledR}$ samples are collected in real cases, they are often diluted and the elements may only have a fraction of their original concentration from the quality control solution. Solidified samples may also be left on a surface for a long period of time which may lead to some level of degradation. Thus, it is important to know how well samples can be analyzed when the elemental concentrations are not as high as they typically would be in the quality control samples.

To test how well the $266 \mathrm{~nm}$ laser works when working with a diluted sample, the Tracer quality control solution was mixed with the polymer blank solution, which did not contain any of the elements used in SmartWater ${ }^{\circledR}$ formulations, in various amounts. A series of seven dilutions were prepared in total and around $2 \mathrm{~mL}$ of each solution was applied to a glass slide and allowed to dry over a period of 48 hours. These solutions

contained $\frac{3}{4}, \frac{2}{3}, \frac{1}{2}, \frac{1}{3}, \frac{1}{4}, \frac{1}{5}$, and $\frac{1}{10}$ of the original elemental concentrations used in the Tracer QC solution. The laser used the optimized parameters found in the previous chapter for collection. Then, the detected elements, along with their signal to noise ratios, were recorded and compared to the results given using just the Tracer QC solution. Table 3 shows that when the elements in the QC tracer solution were at $\frac{3}{4}$ of their original concentration, $\mathrm{Ba}, \mathrm{Nb}, \mathrm{Nd}, \mathrm{Sm}$, and $\mathrm{Tm}$ could not be detected and most of the elements that were found had a reduced $\mathrm{S} / \mathrm{N}$ ratio. Table 4 shows that when the elements in the QC 
tracer solution were at $\frac{2}{3}$ of their original concentration, both Er and Gd could not be observed in addition to the undetected elements from the $\frac{3}{4}$ dilution. At half the Tracer QC concentration (Table 5), the elements Ho, and Lu could not be detected in addition to what could not be seen before. When the tracer QC solution was diluted by a factor of 3, the elements $\mathrm{Ce}$ and La could not be observed in addition to the elements that could not be identified in the previous dilutions as is seen in Table 6. When the QC solution was diluted to a fourth of its concentration, the only elements that could be detected were yttrium and ytterbium (Table 7) and at a fifth of the original Tracer QC solution, the only element that could be seen was ytterbium (Table 8). Finally, when the QC solution was diluted to a tenth of its original concentration, no elements could be identified.

Table 3: Elements detected using $266 \mathrm{~nm}$ laser along with their respective wavelengths used for identification and their concentration when elements in the tracer QC solution were at $\frac{3}{4}$ of their original concentration

\begin{tabular}{|c|c|c|c|}
\hline Element & $\begin{array}{c}\text { Wavelength } \\
(\mathbf{n m})\end{array}$ & $\begin{array}{c}\text { Concentration } \\
(\mathbf{p p m})\end{array}$ & $\begin{array}{c}\text { S/N } \\
\text { Ratio }\end{array}$ \\
\hline $\mathrm{Ce}(\mathrm{II})$ & 418.660 & 28.5 & 66 \\
\hline $\mathrm{Dy}(\mathrm{I})$ & 421.172 & 39.75 & 44 \\
\hline $\mathrm{Er}(\mathrm{II})$ & 390.631 & 40.5 & 94 \\
\hline $\mathrm{Eu}(\mathrm{I})$ & 459.403 & 51 & 217 \\
\hline $\mathrm{Ga}(\mathrm{I})$ & 403.299 & 20.25 & 30 \\
\hline $\mathrm{Gd}(\mathrm{II})$ & 336.223 & 39 & 38 \\
\hline $\mathrm{Ho}(\mathrm{II})$ & 389.102 & 40.5 & 90 \\
\hline $\mathrm{In}(\mathrm{I})$ & 451.131 & 30.75 & 96 \\
\hline $\mathrm{La}(\mathrm{II})$ & 394.910 & 35.25 & 80 \\
\hline $\mathrm{Lu}(\mathrm{II})$ & 355.444 & 42 & 44 \\
\hline $\mathrm{Mo}(\mathrm{I})$ & 379.825 & 42 & 86 \\
\hline $\mathrm{Y}$ (II) & 371.030 & 24.75 & 52 \\
\hline $\mathrm{Yb}(\mathrm{II})$ & 369.419 & 42 & 153 \\
\hline
\end{tabular}


Table 4: Elements detected using $266 \mathrm{~nm}$ laser along with their respective wavelengths used for identification and their concentration when elements in the tracer QC solution were at $\frac{2}{3}$ of their original concentration

\begin{tabular}{|c|c|c|c|}
\hline Element & $\begin{array}{c}\text { Wavelength } \\
(\mathbf{n m})\end{array}$ & $\begin{array}{c}\text { Concentration } \\
(\mathbf{p p m})\end{array}$ & $\begin{array}{c}\text { S/N } \\
\text { Ratio }\end{array}$ \\
\hline $\mathrm{Ce}(\mathrm{II})$ & 418.660 & 25.3 & 62 \\
\hline $\mathrm{Dy}(\mathrm{I})$ & 421.172 & 35.3 & 41 \\
\hline $\mathrm{Eu}(\mathrm{I})$ & 459.403 & 45.3 & 164 \\
\hline $\mathrm{Ga}(\mathrm{I})$ & 403.299 & 18 & 22 \\
\hline $\mathrm{Ho}(\mathrm{II})$ & 389.102 & 36 & 51 \\
\hline $\mathrm{In}(\mathrm{I})$ & 451.131 & 27.3 & 65 \\
\hline $\mathrm{La}(\mathrm{II})$ & 394.910 & 31.3 & 80 \\
\hline $\mathrm{Lu}(\mathrm{II})$ & 355.444 & 37.3 & 36 \\
\hline $\mathrm{Mo}(\mathrm{I})$ & 379.825 & 37.3 & 77 \\
\hline $\mathrm{Y}(\mathrm{II})$ & 371.030 & 22 & 51 \\
\hline $\mathrm{Yb}$ (II) & 369.419 & 37.3 & 144 \\
\hline
\end{tabular}

Table 5: Elements detected using $266 \mathrm{~nm}$ laser along with their respective wavelengths used for identification and their concentration when the tracer QC solution was diluted by a factor of 2 .

\begin{tabular}{|c|c|c|c|}
\hline Element & $\begin{array}{c}\text { Wavelength } \\
(\mathbf{n m})\end{array}$ & $\begin{array}{c}\text { Concentration } \\
(\mathbf{p p m})\end{array}$ & $\begin{array}{c}\text { S/N } \\
\text { Ratio }\end{array}$ \\
\hline $\mathrm{Ce}(\mathrm{II})$ & 418.660 & 19 & 58 \\
\hline $\mathrm{Dy}(\mathrm{I})$ & 421.172 & 26.5 & 35 \\
\hline $\mathrm{Eu}(\mathrm{I})$ & 459.403 & 34 & 148 \\
\hline $\mathrm{Ga}(\mathrm{I})$ & 403.299 & 13.5 & 21 \\
\hline $\mathrm{In}(\mathrm{I})$ & 451.131 & 20.5 & 58 \\
\hline $\mathrm{La}(\mathrm{II})$ & 394.910 & 23.5 & 76 \\
\hline $\mathrm{Mo}(\mathrm{I})$ & 379.825 & 28 & 23 \\
\hline $\mathrm{Y}$ (II) & 371.030 & 16.5 & 48 \\
\hline $\mathrm{Yb}$ (II) & 369.419 & 28 & 141 \\
\hline
\end{tabular}


Table 6: Elements detected using $266 \mathrm{~nm}$ laser along with their respective wavelengths used for identification and their concentration when the QC solution was diluted by a factor of 3 .

\begin{tabular}{|c|c|c|c|}
\hline Element & $\begin{array}{c}\text { Wavelength } \\
(\mathbf{n m})\end{array}$ & $\begin{array}{c}\text { Concentration } \\
(\mathbf{p p m})\end{array}$ & $\begin{array}{c}\text { S/N } \\
\text { Ratio }\end{array}$ \\
\hline $\mathrm{Dy}(\mathrm{I})$ & 421.172 & 17.67 & 31 \\
\hline $\mathrm{Eu}(\mathrm{I})$ & 459.403 & 22.67 & 131 \\
\hline $\mathrm{Ga}(\mathrm{I})$ & 403.299 & 9 & 57 \\
\hline $\mathrm{In}(\mathrm{I})$ & 451.131 & 13.67 & 52 \\
\hline $\mathrm{Mo}(\mathrm{I})$ & 379.825 & 18.67 & 37 \\
\hline $\mathrm{Y}(\mathrm{II})$ & 371.030 & 11 & 41 \\
\hline $\mathrm{Yb}(\mathrm{II})$ & 369.419 & 18.67 & 78 \\
\hline
\end{tabular}

Table 7: Elements detected using $266 \mathrm{~nm}$ laser along with their respective wavelengths used for identification and their concentration when the QC solution was diluted by a factor of 4 .

\begin{tabular}{|c|c|c|c|}
\hline Element & $\begin{array}{c}\text { Wavelength } \\
(\mathbf{n m})\end{array}$ & $\begin{array}{c}\text { Concentration } \\
(\mathbf{p p m})\end{array}$ & $\begin{array}{c}\text { S/N } \\
\text { Ratio }\end{array}$ \\
\hline $\mathrm{Y}$ (II) & 371.030 & 8.25 & 35 \\
\hline $\mathrm{Yb}$ (II) & 369.419 & 14 & 98 \\
\hline
\end{tabular}

Table 8: Elements detected using $266 \mathrm{~nm}$ laser along with their respective wavelengths used for identification and their concentration when the QC solution was diluted by a factor of 5 .

\begin{tabular}{|c|c|c|c|}
\hline Element & $\begin{array}{c}\text { Wavelength } \\
\text { (nm) }\end{array}$ & $\begin{array}{c}\text { Concentration } \\
(\mathbf{p p m})\end{array}$ & $\begin{array}{c}\text { S/N } \\
\text { Ratio }\end{array}$ \\
\hline $\mathrm{Yb}$ (II) & 369.419 & 11.2 & 77 \\
\hline
\end{tabular}

\section{EFFECT OF DILUTIONS ON 1064 NM LASER RESULTS}

The same dilutions were analyzed using the $1064 \mathrm{~nm}$ laser. Since it is a more powerful laser than the $266 \mathrm{~nm}$ laser, and thus able to ablate more of the sample, it was expected that the $1064 \mathrm{~nm}$ laser would show greater persistence with the number of elements it could detect. While the $266 \mathrm{~nm}$ laser detected 13 elements when the elements 
at $\frac{3}{4}$ of their original concentration in the Tracer QC sample, the $1064 \mathrm{~nm}$ laser was able to find 15 elements (Table 9). The elements Gd and Lu could not be detected with the 1064 $\mathrm{nm}$ laser while they could be found using the $266 \mathrm{~nm}$ laser. However, the $1064 \mathrm{~nm}$ laser detected the elements $\mathrm{Nb}, \mathrm{Pr}, \mathrm{Sm}$, and Tm when they previously could not be found when the sample was analyzed with the $266 \mathrm{~nm}$ laser. In addition, while the $266 \mathrm{~nm}$ laser had slightly higher S/N ratios for Er, Ho, La, and Y, the $1064 \mathrm{~nm}$ laser had higher values for all of the other elements found using both machines.

Table 9: Elements detected using $1064 \mathrm{~nm}$ laser along with their respective wavelengths used for identification and their concentration when elements in the tracer QC solution were at $\frac{3}{4}$ of their original concentration

\begin{tabular}{|c|c|c|c|}
\hline Element & $\begin{array}{c}\text { Wavelength } \\
\text { (nm) }\end{array}$ & $\begin{array}{c}\text { Concentrati } \\
\text { on (ppm) }\end{array}$ & S/N Ratio \\
\hline $\mathrm{Ce}(\mathrm{II})$ & 418.660 & 28.5 & 71 \\
\hline $\mathrm{Dy}(\mathrm{I})$ & 421.172 & 39.75 & 103 \\
\hline $\mathrm{Er}$ (II) & 390.631 & 40.5 & 116 \\
\hline $\mathrm{Eu}(\mathrm{I})$ & 459.403 & 51 & 346 \\
\hline $\mathrm{Ga}(\mathrm{I})$ & 403.299 & 20.25 & 40 \\
\hline $\mathrm{Ho}(\mathrm{II})$ & 389.102 & 40.5 & 65 \\
\hline $\mathrm{In}(\mathrm{I})$ & 451.131 & 30.75 & 147 \\
\hline $\mathrm{La}(\mathrm{II})$ & 394.910 & 35.25 & 67 \\
\hline $\mathrm{Mo}(\mathrm{I})$ & 379.825 & 42 & 173 \\
\hline $\mathrm{Nb}(\mathrm{II})$ & 405.894 & 74.25 & 29 \\
\hline $\mathrm{Pr}(\mathrm{I})$ & 469.577 & 48 & 95 \\
\hline $\mathrm{Sm}(\mathrm{I})$ & 429.674 & 37.5 & 53 \\
\hline $\mathrm{Tm}(\mathrm{I})$ & 409.419 & 41.25 & 54 \\
\hline $\mathrm{Y} \mathrm{(II)}$ & 371.030 & 24.75 & 49 \\
\hline $\mathrm{Yb}(\mathrm{II})$ & 369.419 & 42 & 365 \\
\hline
\end{tabular}


When the QC solution was diluted to $\frac{2}{3}$ of its original concentration, the $1064 \mathrm{~nm}$ laser was still able to detect 14 elements (Table 10). Cerium was not able to be found in this solution. While the $266 \mathrm{~nm}$ laser was still able to identify $\mathrm{Ce}$ and $\mathrm{Lu}$ at this dilution while the $1064 \mathrm{~nm}$ laser could not, it was only able to detect 11 elements. Also, the S/N ratios were only higher for $\mathrm{Ho}, \mathrm{La}$, and $\mathrm{Y}$ when using the $266 \mathrm{~nm}$ laser compared to the $1064 \mathrm{~nm}$ laser. All other elements found using the $1064 \mathrm{~nm}$ laser had higher $\mathrm{S} / \mathrm{N}$ values than the $266 \mathrm{~nm}$ laser.

Table 10: Elements detected using $1064 \mathrm{~nm}$ laser along with their respective wavelengths used for identification and their concentration when elements in the tracer QC solution were at $\frac{2}{3}$ of their original concentration

\begin{tabular}{|c|c|c|c|}
\hline Element & $\begin{array}{c}\text { Wavelength } \\
(\mathbf{n m})\end{array}$ & $\begin{array}{c}\text { Concentration } \\
(\mathbf{p p m})\end{array}$ & $\begin{array}{c}\text { S/N } \\
\text { Ratio }\end{array}$ \\
\hline $\mathrm{Dy}(\mathrm{I})$ & 421.172 & 35.3 & 71 \\
\hline $\mathrm{Er}(\mathrm{II})$ & 390.631 & 36 & 108 \\
\hline $\mathrm{Eu}(\mathrm{I})$ & 459.403 & 45.3 & 332 \\
\hline $\mathrm{Ga}(\mathrm{I})$ & 403.299 & 18 & 33 \\
\hline $\mathrm{Ho}(\mathrm{II})$ & 389.102 & 36 & 45 \\
\hline $\mathrm{In}(\mathrm{I})$ & 451.131 & 27.3 & 131 \\
\hline $\mathrm{La}(\mathrm{II})$ & 394.910 & 31.3 & 29 \\
\hline $\mathrm{Mo}(\mathrm{I})$ & 379.825 & 37.3 & 171 \\
\hline $\mathrm{Nb}(\mathrm{II})$ & 405.894 & 66 & 27 \\
\hline $\mathrm{Pr}(\mathrm{I})$ & 469.577 & 42.67 & 92 \\
\hline $\mathrm{Sm}(\mathrm{I})$ & 429.674 & 33.3 & 46 \\
\hline $\mathrm{Tm}(\mathrm{I})$ & 409.419 & 36.67 & 47 \\
\hline $\mathrm{Y} \mathrm{(II)}$ & 371.030 & 22 & 47 \\
\hline $\mathrm{Yb}(\mathrm{II})$ & 369.419 & 37.3 & 327 \\
\hline
\end{tabular}

Once the Tracer QC solution was diluted to half of its original concentration, the $1064 \mathrm{~nm}$ laser, like its counterpart, was only able to detect nine elements (Table 11). While 
the $266 \mathrm{~nm}$ laser was able to identify Ce, Dy, La, and Y, the $1064 \mathrm{~nm}$ laser could detect Er, $\mathrm{Ho}, \mathrm{Nb}$, and Pr. Both lasers were still able to identify Eu, Ga, In, Mo, and $\mathrm{Yb}$. The S/N ratios for these elements were anywhere between 1.43 and 2.48 times higher with the 1064 $\mathrm{nm}$ laser compared to when the $266 \mathrm{~nm}$ laser was used. Table 12 shows what elements could be seen when the Tracer QC solution was at a third of its original concentration. While no elements were lost from the previous dilution, their corresponding $\mathrm{S} / \mathrm{N}$ ratios decreased in value (except for $\mathrm{Nb}$ which had the same value between both dilutions). The $1064 \mathrm{~nm}$ laser was able to identify more elements when the Tracer QC solution was diluted by a factor of three compared to the $266 \mathrm{~nm}$ laser. No elements were lost with the $1064 \mathrm{~nm}$ laser when the QC solution was diluted by a factor of four from the previous dilution. When the QC solution was diluted by a factor of five, only four elements could still be detected using the $1064 \mathrm{~nm}$ laser (Table 14), compared to only one element persisting at this dilution when the $266 \mathrm{~nm}$ laser was used. While the $1064 \mathrm{~nm}$ laser was able to detect more elements for most of the dilutions, both machines could not identify any elements when the Tracer QC solution was diluted by a factor of ten. 
Table 11: Elements detected using $1064 \mathrm{~nm}$ laser along with their respective wavelengths used for identification and their concentration when the tracer QC solution was diluted by a factor of 2 .

\begin{tabular}{|c|c|c|c|}
\hline Element & $\begin{array}{c}\text { Wavelength } \\
(\mathbf{n m})\end{array}$ & $\begin{array}{c}\text { Concentration } \\
(\mathbf{p p m})\end{array}$ & $\begin{array}{c}\text { S/N } \\
\text { Ratio }\end{array}$ \\
\hline $\mathrm{Er}(\mathrm{II})$ & 390.631 & 27 & 55 \\
\hline $\mathrm{Eu}(\mathrm{I})$ & 459.403 & 34 & 300 \\
\hline $\mathrm{Ga}(\mathrm{I})$ & 403.299 & 13.5 & 30 \\
\hline $\mathrm{Ho}(\mathrm{II})$ & 389.102 & 27 & 30 \\
\hline $\mathrm{In}(\mathrm{I})$ & 451.131 & 20.5 & 126 \\
\hline $\mathrm{Mo}(\mathrm{I})$ & 379.825 & 28 & 57 \\
\hline $\mathrm{Nb}(\mathrm{II})$ & 405.894 & 49.5 & 24 \\
\hline $\mathrm{Pr}(\mathrm{II})$ & 469.577 & 32 & 88 \\
\hline $\mathrm{Yb}$ (II) & 369.419 & 28 & 207 \\
\hline
\end{tabular}

Table 12: Elements detected using $1064 \mathrm{~nm}$ laser along with their respective wavelengths used for identification and their concentration when the tracer QC solution was diluted by a factor of 3 .

\begin{tabular}{|c|c|c|c|}
\hline Element & $\begin{array}{c}\text { Wavelength } \\
(\mathbf{n m})\end{array}$ & $\begin{array}{c}\text { Concentration } \\
(\mathbf{p p m})\end{array}$ & $\begin{array}{c}\text { S/N } \\
\text { Ratio }\end{array}$ \\
\hline $\mathrm{Er}$ (II) & 390.631 & 18 & 48 \\
\hline $\mathrm{Eu}(\mathrm{I})$ & 459.403 & 22.67 & 222 \\
\hline $\mathrm{Ga}(\mathrm{I})$ & 403.299 & 9 & 20 \\
\hline $\mathrm{Ho}$ (II) & 389.102 & 18 & 22 \\
\hline $\mathrm{In}(\mathrm{I})$ & 451.131 & 13.67 & 122 \\
\hline $\mathrm{Mo}$ (I) & 379.825 & 18.67 & 53 \\
\hline $\mathrm{Nb}$ (II) & 405.894 & 33 & 24 \\
\hline $\mathrm{Pr}$ (II) & 469.577 & 21.3 & 72 \\
\hline $\mathrm{Yb}$ (II) & 369.419 & 18.67 & 195 \\
\hline
\end{tabular}


Table 13: Elements detected using $1064 \mathrm{~nm}$ laser along with their respective wavelengths used for identification and their concentration when the tracer QC solution was diluted by a factor of 4 .

\begin{tabular}{|c|c|c|c|}
\hline Element & $\begin{array}{c}\text { Wavelength } \\
(\mathbf{n m})\end{array}$ & $\begin{array}{c}\text { Concentration } \\
(\mathbf{p p m})\end{array}$ & $\begin{array}{c}\text { S/N } \\
\text { Ratio }\end{array}$ \\
\hline $\mathrm{Er}$ (II) & 390.631 & 13.5 & 38 \\
\hline $\mathrm{Eu}(\mathrm{I})$ & 459.403 & 17 & 207 \\
\hline $\mathrm{Ga}(\mathrm{I})$ & 403.299 & 6.75 & 18 \\
\hline $\mathrm{Ho}(\mathrm{II})$ & 389.102 & 13.5 & 20 \\
\hline $\mathrm{In}(\mathrm{I})$ & 451.131 & 10.25 & 107 \\
\hline $\mathrm{Mo}(\mathrm{I})$ & 379.825 & 14 & 52 \\
\hline $\mathrm{Nb}$ (II) & 405.894 & 24.75 & 19 \\
\hline $\mathrm{Pr}$ (II) & 469.577 & 16 & 35 \\
\hline $\mathrm{Yb}$ (II) & 369.419 & 14 & 161 \\
\hline
\end{tabular}

Table 14: Elements detected using $1064 \mathrm{~nm}$ laser along with their respective wavelengths used for identification and their concentration when the QC solution was diluted by a factor of 5 .

\begin{tabular}{|c|c|c|c|}
\hline Element & $\begin{array}{c}\text { Wavelength } \\
(\mathbf{n m})\end{array}$ & $\begin{array}{c}\text { Concentration } \\
(\mathbf{p p m})\end{array}$ & $\begin{array}{c}\text { S/N } \\
\text { Ratio }\end{array}$ \\
\hline $\mathrm{Eu}(\mathrm{I})$ & 459.403 & 13.6 & 127 \\
\hline $\mathrm{In}(\mathrm{I})$ & 451.131 & 8.2 & 34 \\
\hline $\mathrm{Mo}(\mathrm{I})$ & 379.825 & 11.2 & 40 \\
\hline $\mathrm{Yb}(\mathrm{II})$ & 369.419 & 11.2 & 97 \\
\hline
\end{tabular}

\section{DIFFERENT QUALITY CONTROL SOLUTIONS}

While the Tracer quality control solution contains the most elements, it is not the only tagging system used by SmartWater ${ }^{\circledR}$. Three other solutions, including the Index, High Temperature, and Heavy-Duty Marker, are utilized for different purposes. The Index solution is similar to the Tracer solution in that it also starts off as a liquid but will solidify after application. It does have a few differences though. Most notably, it is often not used to mark objects. Instead, the solution is more commonly used to mark a criminal at an 
active crime scene. During a breaking and entering scenario, the index solution is deployed, where it lands and later dries on a perpetrator without bringing harm to him or her. It marks the perpetrator by using a spray device that is fitted to a commercial premise which is subsequently linked to a burglar alarm. It also only has a polymer concentration of around two percent, meaning that, compared to the Tracer solution, more of the liquid will evaporate when the solution dries, thus forming a thinner, but still highly recoverable, layer. The Index solution contains the same elements as the Tracer sample with the concentration of the elements being the same. Samples of the Index solution were made by applying 2-3 drops of the liquid onto a cotton swab and allowing the sample to dry and solidify overnight. All of the optimal parameters were used for analysis except for the stage displacement since the solution would only solidify into a thin layer and no extra sample would be ablated if the focus was changed.

Table 15 gives the results when the Index QC solution was examined using the 266 nm laser. While the Tracer solution was able to detect 18 elements, the index solution was able to identify only 16 with $\mathrm{Gd}, \mathrm{Lu}$, and $\mathrm{Nb}$ not being able to be detected. However, $\mathrm{Tb}$ was able to be seen in the Index solution where it previously could not be seen in the Tracer QC solution. While it is not known why Tb could be seen in this sample when it could not be seen in the Tracer solution, the loss of $\mathrm{Gd}, \mathrm{Lu}$, and $\mathrm{Nb}$ could be caused by less sample ablation as a result of the sample only being able to form a thin layer during solidification.

The High Temperature solution is primarily employed when an object or scenario needs a solution that is stable at very high temperatures. While the Tracer and Index solutions can persist in most environments, the High Temperature solution specializes in 
conditions that are so warm that the other solutions begin to become unstable. For example, if one wishes to mark the catalytic converter or any exhaust component on a vehicle, the High Temperature marker must be used since the other solutions will likely not persist after the vehicle is turned on. Compared to the Index and Tracer solutions, the High Temperature marker has a much higher concentration of elements in order ensure a good recovery. Also, the High Temperature marker only makes use of 23 elements (Bi, Ce, Dy, Er, Eu, Ga, Ge, Gd, Hf, Ho, In, La, Lu, Mn, Mo, Nd, Pr, Sm, Tb, Tm, W, Y and Yb) and only has a polymer concentration of two percent. Samples were made by applying 2-3 drops of the liquid onto a cotton swab and allowing the sample to dry and solidify overnight.

Table 15: Elements detected using $266 \mathrm{~nm}$ laser along with their respective wavelengths used for identification and their concentration in the Index QC solution.

\begin{tabular}{|c|c|c|c|}
\hline Element & $\begin{array}{c}\text { Wavelength } \\
\text { (nm) }\end{array}$ & $\begin{array}{c}\text { Concentration } \\
\text { (ppm) }\end{array}$ & $\begin{array}{c}\text { S/N } \\
\text { Ratio }\end{array}$ \\
\hline $\mathrm{Ba}(\mathrm{I})$ & 455.403 & 126 & 101 \\
\hline $\mathrm{Ce}$ (II) & 418.660 & 38 & 44 \\
\hline Dy (II) & 353.170 & 53 & 53 \\
\hline Er (II) & 390.631 & 54 & 42 \\
\hline $\mathrm{Eu}(\mathrm{I})$ & 459.403 & 68 & 319 \\
\hline $\mathrm{Ga}(\mathrm{I})$ & 417.204 & 27 & 46 \\
\hline Ho (II) & 389.102 & 54 & 115 \\
\hline In (I) & 451.131 & 41 & 151 \\
\hline $\mathrm{La}$ (II) & 394.910 & 47 & 39 \\
\hline Mo (I) & 379.825 & 56 & 37 \\
\hline $\mathrm{Nd}$ (II) & 401.225 & 49 & 34 \\
\hline $\mathrm{Sm}(\mathrm{II})$ & 359.260 & 50 & 70 \\
\hline $\mathrm{Tb}(\mathrm{I})$ & 375.935 & 70 & 69 \\
\hline $\operatorname{Tm}(\mathrm{I})$ & 409.419 & 55 & 40 \\
\hline Y (II) & 371.030 & 33 & 117 \\
\hline $\mathrm{Yb}$ (II) & 369.419 & 56 & 128 \\
\hline
\end{tabular}


Of the 23 elements present in the High Temperature Marker sample, 16 were able to be detected with the $266 \mathrm{~nm}$ laser (Table 16). Since the elemental concentrations were higher in solution than they were with the Tracer and Index solutions, most of the $\mathrm{S} / \mathrm{N}$ ratios were far higher as a result. While not every element had a higher $\mathrm{S} / \mathrm{N}$, as is the case with $\mathrm{Er}, \mathrm{Eu}$, and Mo, the elements that did have a higher value had an increase of anywhere between 1.08 and 7.22 times the ratios seen in the Tracer QC sample.

Table 16: Elements detected using the $266 \mathrm{~nm}$ laser along with their respective wavelengths used for identification in the High Temperature QC solution.

\begin{tabular}{|c|c|c|}
\hline Element & $\begin{array}{l}\text { Wavelength } \\
(\mathbf{n m})\end{array}$ & $\begin{array}{l}\text { S/N } \\
\text { Ratio }\end{array}$ \\
\hline $\mathrm{Ce}$ (II) & 418.660 & 131 \\
\hline Dy (II) & 353.170 & 93 \\
\hline $\operatorname{Er}(\mathrm{II})$ & 390.631 & 91 \\
\hline $\mathrm{Eu}(\mathrm{I})$ & 459.403 & 519 \\
\hline $\mathrm{Ga}(\mathrm{I})$ & 417.204 & 260 \\
\hline Gd (II) & 336.223 & 116 \\
\hline Ho (II) & 389.102 & 175 \\
\hline In (I) & 451.131 & 192 \\
\hline $\mathrm{La}(\mathrm{II})$ & 394.910 & 500 \\
\hline $\mathrm{Lu}$ (II) & 355.444 & 148 \\
\hline Mo (I) & 379.825 & 54 \\
\hline Nd (II) & 401.225 & 109 \\
\hline $\mathrm{Tb}(\mathrm{I})$ & 375.935 & 162 \\
\hline $\operatorname{Tm}(\mathrm{I})$ & 409.419 & 132 \\
\hline Y (II) & 371.030 & 371 \\
\hline $\mathrm{Yb}$ (II) & 369.419 & 589 \\
\hline
\end{tabular}

The Heavy-Duty Transferable Marker is far different from the other solutions. It is designed for use only in controlled covert operations that are managed by highly trained personnel. Instead of being a liquid that solidifies after application, the Heavy-Duty 
Transferable Marker is a grease-based and non-drying gel. It can transfer onto anyone or anything that comes into contact with an area marked with the gel. While it does not solidify, the gel is still mostly invisible to the naked eye (with the exception of showing up as a greasy mark on some surfaces) while still fluorescing yellow when exposed to a UV light. Like with the High Temperature marker, the Heavy-Duty Transferable Marker has a higher concentration of elements compared to the Tracer and Index solutions. It contains up to 23 elements made up of Bi, Ce, Dy, Er, Eu, Ga, Ge, Gd, Hf, Ho, In, La, Lu, Mn, Mo, $\mathrm{Nd}, \mathrm{Pr}, \mathrm{Sm}, \mathrm{Tb}, \mathrm{Tm}, \mathrm{W}, \mathrm{Y}$ and $\mathrm{Yb}$. Samples were made by applying around $1 \mathrm{~mL}$ of grease to a cotton swab and allowing it to settle overnight.

Table 17: Elements detected using J200 laser along with their respective wavelengths used for identification in the heavy duty Marker QC solution.

\begin{tabular}{|c|c|c|}
\hline Element & $\begin{array}{l}\text { Wavelength } \\
\text { (nm) }\end{array}$ & $\begin{array}{l}\text { S/N } \\
\text { Ratio }\end{array}$ \\
\hline $\mathrm{Ce}$ (II) & 418.660 & 122 \\
\hline Dy (II) & 353.170 & 198 \\
\hline $\operatorname{Er}(\mathrm{II})$ & 390.631 & 229 \\
\hline $\mathrm{Eu}(\mathrm{I})$ & 459.403 & 538 \\
\hline $\mathrm{Ga}(\mathrm{I})$ & 417.204 & 173 \\
\hline Gd (II) & 336.223 & 41 \\
\hline Ho (II) & 389.102 & 260 \\
\hline In (I) & 451.131 & 558 \\
\hline La (II) & 394.910 & 87 \\
\hline $\mathrm{Lu}$ (II) & 355.444 & 51 \\
\hline Mo (I) & 379.825 & 126 \\
\hline $\mathrm{Nd}$ (II) & 401.225 & 52 \\
\hline Sm (II) & 359.260 & 149 \\
\hline $\mathrm{Tb}(\mathrm{I})$ & 375.935 & 114 \\
\hline $\operatorname{Tm}(\mathrm{I})$ & 409.419 & 65 \\
\hline Y (II) & 371.030 & 55 \\
\hline $\mathrm{Yb}$ (II) & 369.419 & 160 \\
\hline
\end{tabular}


The $266 \mathrm{~nm}$ laser was able to identify 17 of the 23 elements used in the HeavyDuty Marker solution. It was able to see the same elements as the High Temperature sample in addition to samarium (Table 17). Six of the elements, including Eu, Gd, Lu, Mo, Y, and $\mathrm{Yb}$ had a lower $\mathrm{S} / \mathrm{N}$ ratio compared to the Tracer Solution. The other 11 elements had a $\mathrm{S} / \mathrm{N}$ that was anywhere between 1.04 and 5.42 times higher than what was found with the Tracer QC sample. While the elements are supposed to have a higher concentration in the Heavy-Duty Marker, the difference between the matrices (gel vs solidified polymer) may explain why not all elements had a higher $\mathrm{S} / \mathrm{N}$ ratio and why any observed increases varied as much as they did. 


\section{CHAPTER 5: INTERPRETATION AND DISCUSSION}

\section{INTERRPRETATION OF RESULTS}

Of the 27 elements present in the Tracer QC sample, the results show that LIBS was able to successfully discriminate between either 18 or 19 elements, depending on the machine that was utilized, at concentrations ranging from 27 to $126 \mathrm{ppm}$. Neither instrument could detect $\mathrm{Bi}, \mathrm{Ge}, \mathrm{Hf}, \mathrm{Ta}, \mathrm{Tb}, \mathrm{Te}, \mathrm{W}$, and $\mathrm{Zr}$ at the concentrations given in the Tracer QC solution. In addition, the $266 \mathrm{~nm}$ laser could not pick up on a single peak belonging to Pr, while the $1064 \mathrm{~nm}$ laser could. This might indicate that the amount of power supplied by the $266 \mathrm{~nm}$ laser was not sufficient enough to excite the element and produce any emission. It could also be possible that the $1064 \mathrm{~nm}$ laser was able to ablate more of the sample which would make it easier to find any elements not previously seen. The $266 \mathrm{~nm}$ laser might be able to identify a peak belonging to Pr if either more sample was ablated or if the concentration inside the solution was increased. This may also be the case with the elements that neither instrument could find. In particular, bismuth was able to be detected in Steven Wise's experiments. However, he was only able to find it when the concentration was raised to around five times that found in the Tracer QC solution. LIBS may be able to identify more elements but their concentrations may have to be higher in the solution for that to happen.

As with the Tracer QC solution, the Index, Heavy-Duty Marker, and High Temperature solutions were able to have most of their elements identified. While LIBS was only able to see 16 of the 27 elements used in the Index QC sample, it could identify terbium which was an element that was not able to be seen in the Tracer QC solution. 
Although the Tracer and Index solution have the same elemental components at the same concentration in solution, the difference between the results likely comes from the different matrices used for analysis. The Tracer solution, due to its high polymer concentration, could be directly applied to a glass slide to dry where it would form a thick enough layer to perform LIBS on. The Index solution had to be applied on a cotton swab since it would not form a thick enough layer for LIBS to be effective. While this means that more solvent evaporates and the elements should have a higher concentration on the sample surface, it also means that less sample is ablated since the solidified layer is far thinner with the Index solution than it is for the Tracer solution. Both the Heavy-Duty and High Temperature solutions had a higher percentage of elements seen compared to the Tracer QC sample. LIBS was able to identify 17 of the 23 elements used in the Heavy-Duty QC solution and 16 of the 23 elements used with the High Temperature QC sample. Since both solutions had higher elemental concentrations compared to the Tracer QC solution, most of the identified elements had a higher $\mathrm{S} / \mathrm{N}$ ratio as a result despite the low polymer concentration and lack of a thick sample layer.

The dilution experiments showed how well LIBS can work when a collected sample has elemental concentrations below that found in an undiluted solution. When the Tracer QC solution was diluted by a factor of 10 , neither instrument could find peaks belonging to any of the elements. The spectrum was indistinguishable from the polymer blank, which did not contain any of the elements used in the QC solutions. In fact, both instruments were only able to successfully distinguish between nine elements when the QC sample was diluted by a factor of two. This is important, since when collecting samples, it is common for investigators to use methanol on a cotton swab to gather any dried liquid thought to 
contain SmartWater $^{\circledR}$ if a portion of the surface cannot be removed for analysis. The elements, as a result, would likely be at much lower concentrations on the cotton swab which would affect analysis. If even one element cannot be identified in a solution, the sample will not be traced to the correct owner. While the results show that LIBS cannot provide the same level of discrimination as LA-ICP-MS, which can detect all the components at concentrations in the ppb range, it does show some promise that a sample, even when it has undergone degradation or dilution, can still be qualitatively assessed to a degree using LIBS. This is particularly true with the Heavy-Duty and High Temperature solutions which both have higher elemental concentrations than both the Tracer and Index solutions.

As was expected, the $1064 \mathrm{~nm}$ laser appeared to give better results when examining SmartWater ${ }^{\circledR}$ samples. Not only could it identify an element that the $266 \mathrm{~nm}$ could not, it also had a higher degree of discrimination for most of the components found in both instruments. While not every element had a higher S/N ratio with the $1064 \mathrm{~nm}$ laser, 11 of the elements had a value up to five times higher than what was found with the $266 \mathrm{~nm}$ laser. In addition, the $1064 \mathrm{~nm}$ laser showed a greater persistence for detecting elements when the samples were diluted. Although both instruments failed to identify any of the components when the Tracer QC solution was diluted by a factor of 10, the $1064 \mathrm{~nm}$ laser was able to find either an equal or greater amount of elements than the $266 \mathrm{~nm}$ laser at all other dilutions.

A moderate level of error was observed in both machines throughout the course of this research. The percent relative standard deviations (RSD) typically ranged from 5-35\% 
during replicate trials of the same sample. Despite this, the error did not seem to affect the ability of LIBS to determine the presence or absence of an element. Both the $266 \mathrm{~nm}$ and $1064 \mathrm{~nm}$ laser had roughly the same amount of error and neither instrument had a clear advantage when it came to precision. The error may be attributed to different amounts of ablation taking place between each replicate. While the thickness of the solidified Tracer solution was around $1 \mathrm{~mm}$ thick, this was not completely uniform across the entirety of the surface. While any difference in sample thickness is minor, any discrepancy could mean that replicates ablate different amounts of the sample and obtain higher or lower intensities as a result.

\section{LIBS DISCUSSION}

As an alternative to elemental analysis techniques such as ICP-MS and LA-ICPMS, LIBS has shown to be a viable technique capable of discriminating between most of the elements used in the various SmartWater ${ }^{\circledR}$ solutions. While it is not capable of detecting as many elements and is not as sensitive as the ICP-MS techniques, LIBS was able to provide a promising framework that, with some changes to the current SmartWater ${ }^{\circledR}$ formula, can show the same level of discrimination. As it stands, LIBS was able to identify up to 19 of the 27 total elements used at the concentrations given in the Tracer QC solutions which range from 27-126 ppm. Other elements, such as bismuth and terbium, may need to have their concentrations increased in the solution if they are to be detected using LIBS. Wise demonstrated that those elements can be seen but only at concentrations far above what is currently used by SmartWater ${ }^{\circledR}$. Despite some of the limitations, this study has shown that not only can LIBS be used to analyze samples that have SmartWater ${ }^{\circledR}$ directly 
on their surface but it can also be used when one needs to apply a solution to a cotton swab. This is especially true with the Heavy-Duty and High Temperature solutions which have higher elemental concentrations compared to the Tracer and Index solutions. Analysis with LIBS can even occur when the samples need to be diluted or when there may be a limited amount of the analyte.

While this study has shown the potential for commercial LIBS instruments to be utilized by law enforcement, further research may help with exploring further possibilities. For instance, while a LIBS machine can be small enough to bring onto a crime scene, the instruments used for this research are not small enough to be portable and had to be kept in a laboratory. It may be worth studying how well portable machines work in comparison to the ones used for this research since portability is one of the big advantages LIBS has over LA-ICP-MS. In addition, it may be useful to compare instruments developed by other companies to see how well they perform compared to the machines bought for this study. This might provide some insight into not only how useful various instruments can be when analyzing SmartWater ${ }^{\circledR}$ samples but can also show the true potential of LIBS. While the machines used for this study could see at most 19 elements used in SmartWater ${ }^{\circledR}$ solutions, instruments made by other companies may be able to detect more elements or have a higher degree of discrimination. For instance, an instrument with a more powerful laser setup may be able to more adequately excite some of the elements that could not be detected in this study. In addition, while LIBS was used as a semi-quantitative technique for this study, future research may help develop this method so that it can be used quantitatively. This would provide better insight into what the LOD values are for each of the elements and how it compares to ICP-MS. Lastly, other elemental analysis techniques such as XRF, 
which can also be purchased as a portable device, may be worth studying as another alternative to ICP-MS since it is a non-destructive technique with a sensitivity similar to that of LIBS.

\section{CONCLUSION}

As an alternative to LA-ICP-MS, LIBS has shown potential to be utilized by law enforcement as well as other agencies interested in providing the analysis of chemical taggants. While not as sensitive as ICP-MS techniques, LIBS can obtain data much faster and less expensively and with much greater ease of use. In addition, portable LIBS machines have the potential to be used directly at the scene of a crime for analysis thus eliminating the need to collect evidence, chain of custody concerns and evidence contamination and degradation concerns. All of this combined with the fact that LIBS is a much easier device to operate means that, with some refinement to the elemental concentrations used in SmartWater ${ }^{\circledR}$ and instrumental quantitation, the technique can be used by law enforcement to conduct a fast and reliable field analysis on samples utilizing chemical taggants.

Laser induced breakdown spectroscopy is quickly emerging as a practical alternative to other complex elemental analysis approaches such as ICP-MS and even XRF. With further improvements to its quantitative technique and sensitivity, this approach could truly replace LA-ICP-MS as the gold standard for elemental analysis. Specifically, the commercial instruments used for this study have shown great promise for how accessible LIBS can be. The optimal parameters found in this study can be easily replicated for anyone who wishes to purchase a similar LIBS machine. With how cheap it is compared to other 
elemental analysis techniques; most crime labs would be able to obtain an instrument and its ease of use would help ensure that it can be utilized by those who have not undergone special training. 


\section{LIST OF REFEERENCES}

1. R.E. Russo, X.L. Mao, H.C. Liu, J.H. Yoo, S.S. Mao: Appl. Phys. A 69 [Suppl.], S887-S894 (1999).

2. Pasquini, C., Cortex, J., Silva, L., Gonzaga, F. 2007. Laser Induced Breakdown Spectroscopy. J. Braz. Chem. Soc. 18(3): 463-512

3. JR Amirall, S Umpierrez, W Castro, I Gornushkin, J Wineforder, Proceedings of SPIE-Volume 5778-Sensors, and Command, Control, Communications, and Intelligence (C3I) Technologies for Homeland Security and Homeland Defense IV, Orlando, USA, 2005.

4. Caruso, J., Davidson, T., Shen, W., Sheppard, B. 1990. Helium-argon inductively coupled plasma for plasma source mass spectrometry. Journal of Analytical Atomic Spectrometry. 5(8): 697-700.

5. Cremers, D., Radziemski, L. 2006. Handbook of Laser-Induced Breakdown Spectroscopy. West Sussex (England): John Wiley \& Sons Ltd.

6. Wise, S. 2007. Chemical taggant detection and analysis by laser-induced breakdown spectroscopy [thesis]. [Miami (FL)]: Florida International University.

7. Sørensen T., Arppe, R. 2017. Physical unclonable functions generated through chemical methods for anti-counterfeiting. Nature Review Chemistry. 1(3): 1-13.

8. Mauricio, F.G.M, Pralon, A.Z., Talhavini, M., Rodrigues, M.O., Weber, I.T. 2017. Idenification of ANFO: Use of Luminescent Taggants In Post-Blast Residues. Forensic Science International. 275: 8-13.

9. Gooch, J., Goh, H., Daniel, B., Abbate, V., Frascione, N. 2016. Monitoring Criminal Activity through Invisible Fluorescent "Peptide Coding" Taggants. Anal. Chem. 88: 4456-4460.

10. D. Paunescu et al. 2016. Particles with an identity: Tracking and tracing in commodity products. Powder Technology. 291: 344-350

11. Orzel, J., Daszykowski, M. 2017. Recent trends in the use of liquid fuel taggants and their analysis. Trends in Analytical Chemistry. 87: 98-111

12. OECD/EUIPO. Trade in Counterfeit and Pirated Goods: Mapping the Economic Impact (OECD Publishing, 2016).

13. J.-F. Lutz. 2010. Polymer chemistry: a controlled sequence of events, Nat. Chem. 2: 84-85.

14. RG Ewing, DA Atkinson, GA Eiceman, GJ Ewing. 2001. A critical review of ion mobility spectrometry for the detection of explosives and explosive related compounds. Talanta. 54: 515-529. 
15. Institute of Makers of Explosives (IME). http://www.ime.org/dynamic.php?page_id=66

16. SmartWater Technologies Ltd; http://www.smartwater.com

17. Koirtyohann, S. R. 1991. A History of Atomic Absorption Spectrometry. Analytical Chemistry. 63(21): 1024A-1031A.

18. Fischer, A., Hill, S. 2017. Atomic Absorption, Methods and Instrumentation. Plymouth (England): Elsevier Ltd. Encyclopedia of Spectroscopy and Spectrometry (Third Edition); 37-43.

19. XRF Technology. 2017. ThermoFisher Scientific; [accessed 20 January 2020]. https://www.thermofisher.com/us/en/home/industrial/spectroscopy-elementalisotope-analysis/spectroscopy-elemental-isotope-analysis-learningcenter/elemental-analysis-information/xrf-technology.html

20. Pessanha, S., Queralt, I., Carvalho, M., Sampaio, J. 2019. Determination of gold leaf thickness using X-ray fluorescence spectrometry: Accuracy comparison using analytical methodology and Monte Carlo simulations. Applied Radiation and Isotopes. 152: 6-10.

21. Kuisma-Kursula, P. 2000. Accuracy, Precision and Dectection limits of SEMWDS, SEMEDS, and PIXE in the Mutli-Elemental Analysis of Medieval Glass. X-Ray Spectrum. 29:111-118.

22. Hieftje, Gary; et al. 1982. Design and Construction of a Low-Flow, Low-Power Torch for Inductively Coupled Plasma Spectrometry. Applied Spectroscopy. 36(6): 627-631.

23. Most Common Elemental Analysis Techniques. 2019. Azo Materials; [accessed 24 Janurary 2020]. https://www.azom.com/article.aspx?ArticleID=16423

24. Jarvis KE, Gray AL, Houk RS. 1991. Handbook of Inductively Coupled Plasma Mass Spectrometry. London: Blackie and Son.

25. AJ Mank, PR Masson. 1999. A critical assessment of laser ablation ICPMS as an analytical tool for depth analysis in silica based glass samples. J. Anal. At. Spectrom.; 14:1143-1153.

26. RE Russo, X Mao, SS Mao. 2002. The Physics of Laser Ablation in Microchemical Analysis. Anal Chem. 74:70A-77A.

27. Lopez-Moreno, C.; Amponsah-Manager, K.; Smith, B.W.; Gornushkin, I.B.; Omenetto, N.; Palanco, S.; Laserna, J.J.;Winefordner, J.D. 2005. Quantitative analysis of low-alloy steel by microchip laser induced breakdown spectroscopy. $J$. Anal. At. Spectrum. 20: 552-556. 
28. Loebe, K.; Uhl, A.; Lucht, H. 2003. Laser Microanalysis of Glass and Tool Steel Appl. Opt. 42: 6166.

29. Corsi, M.; Cristoforetti, G.; Giuffrida, M.; Hidalgo, M.; Legnaioli, S.; Masotti, L.; Palleschi, V.; Salvetti, A.; Tognoni, E.; Vallebona, C.; Zanini, A. 2005. Archaeometric Analysis of Ancient Copper Artefacts by Laser-Induced Breakdown Spectroscopy Technique. Microchim. Acta. 152: 105-111.

30. Niu, L.; Cho, H.; Song, K.; Cha, H.; Kim, Y.; Lee, Y. 2002. Direct Determination of Strontium in Marine Algae Samples by Laser-Induced Breakdown Spectrometry. Appl. Spectrosc. 56(11): 1511-1514.

31. Gondal, M. A.; Hussain, T. 2006. Determination of poisonous metals in wastewater collected from paint manufacturing plant using laser-induced breakdown spectroscopy. Talanta. 71(1): 73-80. 